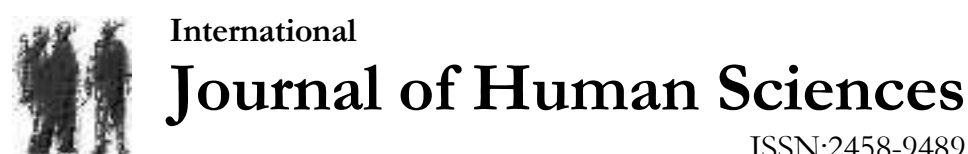

Volume: 18 Issue: 4 Year: 2021

\section{How effect active participation the life satisfaction of individuals ${ }^{1}$}

\author{
Aktif katılım bireylerin yaşam \\ doyumunu nasıl etkiler?
}

\author{
Faik Ardahan ${ }^{2}$
}

\section{Abstract}

The main aim of this research was to compare Life Satisfaction (LS) level of individuals who were participants of different recreational activities with individuals who were nonparticipant with respect to some demographics as age, gender, marital status, personal income, employment type, education level and recreational activities.

The sample of the study is composed of 4214 men and 1287 women totally 5501 individuals. Data were collected from thirteen different researches focused on recreational activities and LS. Nine of the researches were composed of active participants in Mountaineering/Rock Climbing ( $n=426)$, Bicycle Festivals $(n=373)$, Trekking/Hiking $(\mathrm{n}=382)$, Hunting $(\mathrm{n}=187)$, Fishing $(n=367)$, Recreational Motorcycle Users $(\mathrm{n}=947)$, Being Volunteer in a NonGovernmental Organisation $(n=208)$, Singing in recreational choirs as a Chorist $(n=633)$, Recreational bicycle users $(n=682)$ and four of them consist of individuals never done this kind activity before. Such as Never participate in any outdoor activities $(n=538)$, Never Hunting and Fishing $(n=324)$, Never been as a volunteer in any non-governmental organisations $(n=138)$, Never been in a choir as a chorist $(n=296)$. In the analysis of data, besides the descriptive

\section{Özet}

$\mathrm{Bu}$ araştırmanın temel amacı; farklı rekreasyon etkinliklerine katulan bireylerin Yaşam Doyumu (YD) düzeylerini, yaş, cinsiyet, medeni durum, kişisel gelir, istihdam türü, eğitim seviyesi gibi bazı demografik değişkenler açısından değerlendirmek, farklı rekreasyon faaliyetlerinin YD ile ilişkisini incelemek, rekreasyonel faaliyetlere katilan ve katilmayan bireylerin YD düzeylerini karşılaşturmaktır.

Araştırmanın örneklemini 4214 erkek ve 1287 kadın toplam 5501 kişi oluşturmaktadır. Veriler rekreasyonel aktivitelere ve YD'na odaklanan on üç farklı araştırmadan toplanmıştır. Araştırmalardan dokuzu Dağcilık / Kaya Tirmanışı ( $n=426)$, Bisiklet Şenlikleri $(n=373)$, Trekking / Yürüyüş ( $\mathrm{n}=382$ ), Avcilik ( $\mathrm{n}=$ 187), Eğlence Amaçlı Motosiklet Kullanıcıları (n = 947), Bir Sivil Toplum Kuruluşunda Gönüllü Olma ( $n=208)$, Korolarda Korist olarak şark1 söyleme ( $\mathrm{n}=$ 633), Eğlence amaçlı bisiklet kullanıcıları ( $\mathrm{n}=682)$ ve Balıkçılık ( $\mathrm{n}=367$ ) gibi aktivitelere aktif katılımcılardan ve dördü de daha önce hiç bu tür faaliyetler yapmamış olanlardan seçilmiştir. Bunlar; herhangi bir açık alan etkinliğine katılmamış ( $\mathrm{n}=538)$, avcılık ve balıkçlık yapmamış ( $n=324)$, hiçbir sivil toplum kuruluşunda gönüllü olmamış ( $n=138)$,

\footnotetext{
1 This work is the enhanced version of the paper presented at the 6th International Academic Conference on Social Sciences held on 27-28th July 2018 Prague / Czech Republic.

2 Prof. Dr., Akdeniz University, Physical Education and Sport School, Recreation Department, ardahan@akdeniz.edu.tr (iD) Orcid ID: 0000-0003-0293-4707
} 
statistics, Independent Sample t-test and ANOVA test were used, thus to identify the reason of the differences LSD test were applied. All the results were analyzed at the significant level of 0.05 .

Finding demonstrates that being women, married, employed, in middle aged and/or upper, in active leisure life and have higher personal income cause statistically meaningful higher LS then opposites. In addition to this, having active leisure life has positive effect on LS level of individuals. When compared with respect to each demographic variable there are statistically meaningful differences LS levels between individuals who are active participants of some recreational activities and nonparticipate into same activities.

As a result, it can be concluded that for having higher LS level, it is necessary to have active leisure life or active participation in any recreational activities. For this, in each level of education stage, individuals must be educated and motivated how to be an active in their leisure life, what the active life's advantages are and the urban design and infrastructural investments must support and motivate recreational life of urbanites.

Keywords: Active Leisure Life, Recreation, Life Satisfaction.

(Extended English summary is at the end of this document) hiçbir koroda görev almamış ( $\mathrm{n}=296)$ bireylerdir.

Verilerin analizinde betimsel istatistiklerin yanı sira Independent Sample t-testi ve ANOVA testi kullanılarak farklılıkların nedenini belirlemek için LSD testi uygulanmıştır. Tüm sonuçlar 0.05 anlamlilik düzeyinde analiz edilmiştir.

Sonuç olarak, daha yüksek YD seviyesine sahip olmak için, bireylerin aktif serbest zaman hayatına sahip olmasi veya herhangi bir rekreasyonel aktiviteye aktif katılımının gerekli olduğu sonucuna varılabilir. Bunun için, eğitimin her aşamasında bireyler serbest yaşamlarında nasıl aktif olacakları konusunda eğitilmeli ve motive edilmelidir. Aktif yaşamın avantajlarının neler olduğu hakkında farkındalık çalışmaları yapılmalı, kentsel tasarım ve altyapı yattrımları açısından kentlerde yaşayanların rekreasyonel yaşamları desteklemeli ve kişiler motive edilmelidir.

Anahtar Kelimeler: Aktif rekreasyonel yaşam, rekreasyon, yaşam doyumu.

\section{İyilik Halinin Tanımı, Yaşam Doyumu, Sağlık, Mutluluk}

Her insan, yaşamı boyunca daha fazla mutluluk, daha yüksek yaşam memnuniyeti (LS), fiziksel ve zihinsel sağlık (sağlık) ve esenliğe sahip olmak ister. Bunlar hayatın ana belirleyicileridir. Filozoflar, fizikçiler, psikologlar, tıp uzmanı ve diğer tüm bilim adamları ve peygamberler, din adamlan, kişisel gelişim uzmanı, iş sahibi, politikacı, yerel yöneticiler ve diğerleri uzun zamandır iyi, mutlu, tatmin edici, kaliteli yaşam ve bunun nasıl yapılabileceği ile ilgilenmişlerdir. En iyi ve en kısa yolun ne olduğunu sorgulamışlardır. Tüm bireylerin/kurumların hepsi bu dört belirleyiciye ulaşmak için, ortak ve/veya farklı tavsiyelerde bulunmuşlardır. Bunların hepsi başkaları üzerinde bir etkiye sahiptir ve onlardan etkilenir.

Karmaşıklığı azaltmak için, onları kısaca tanımlamak daha iyidir.

Sağllk (Wellness) 1950'lere kadar bütüncül bir fiziksel, zihinsel, ruhsal sağlik ve sosyal refah kavramı olarak tanımlanırken, daha sonra fiziksel, mesleki, sosyal, ruhsal, entelektüel ve duygusal olarak altı boyutta ele alınmış ve incelenmiştir. Sağllk, sabit bir durumdan ziyade sürekli bir durumdur. Kapsamlı fiziksel, sosyal, zihinsel, ruhsal ve kültürel boyutlara bütüncül bir yaklaşımdır. Aynı zamanda wellness bireyin potansiyelini tanımlar ve bireylerin kabiliyetine uygun en yüksek sağlık düzeyine sahip olmalarına yardımcı olur. Kişinin kendini tanıması ve kendiyle bütünleşmesi, üst düzey iyilik halinin 
ana unsurlarıdır. Bireylerin zihinsel sağlığı kendi sorumluluğundadır ve başkasına devredilemez (Miller, 2005).

İyilik Hali (WB), genel olarak bireyin veya bir grubun pozitif iyilik halini ifade etmek için tanımlanır ve üç boyutu vardır. Bunlardan ilki; deneyim, alg1 ve değerleri ilgilendiren öznel boyuttur (anlam / anlamsızlık, umutlar, korkular ve özlemler, benlik kavramı ve kişilik, güven ve güven). İkincisi; yaşam standartlarını ilgilendiren maddi boyut ve pratik refahtır (gelir, hizmetlere ve olanaklara erişim, zenginlik ve varlık, fiziksel sağllk, istihdam ve geçim faaliyetleri, çevresel kalite). Üçüncüsü; kişisel ve sosyal ilisskileri ilgilendiren ilişkilerdir (destek ve yükümlülük ağları, sosyal, politik ve kültürel kimlikler ve eşitsizlikler, sevgi ve ilgi ilişkileri, şiddet, çatışma ve (iç) güvenlik gibi). WB herkes için nesnel veya eşit olmayan, bu üç boyutun öznel bir korelasyon/kombinasyon şeklidir. WB'nin yaygın formülasyonu şu şekildedir; "İyi Yapmak İyi Hissettirir, İyiyi yapmak İyiyi Hissettirir". Kendini iyi ifade etmek, kendini iyi hissetmek, WB'nin öznel boyutunu tanımlar. Bu formülün ikinci kısmı genellikle gelişmekte olan ülkeler için kullanılır. "İyilik yapmak” birçok kısıtlayıcıyı koşul, altyapı, ücret, firsat, malzeme gibi unsurlar tarafindan etkilenen bir olgu iken "iyi hissetmek" ahlaki duyguyu ve sağlı̆̆1 ifade eder (White, 2008).

Mutluluğu tanımlamak kolay değildir. İnsanın temel motivasyonu olarak kabul edilebilir. Layand (2003) bunu "iyi hissetmek, hayattan zevk almak ve harika olduğunu hissetmek" olarak tanımlamaktadır ve Diener (1984) bunu öznel bir fenomen olarak tanımlamaktadır. Mutluluk bazen anlık bir ruh halidir ve bazen bir ömür boyu özlenen ve istenen durumdur. Bazen bir hedefe ulaşmak, bazen bir hedefe yolculuk yapmaktır.

Yakın geçmişe kadar iyilik ve mutluluğun hazcılık ile ilişkili olduğu kabul edilmiştir. Hazcılık doktrini, esenlik ve mutluluğa ulaşmanın en önemli yollarından biriydi. Aristuppus (MÖ 435-366) ise mutluluğu, acıyı en aza indirmeye ve zevki en üst düzeye çıkarmaya odaklanmış ve hedonižm görüşünü ortaya atmıştır. Bu kavramı daha sonra Epicurus (MÖ 342-270) devam ettirmiştir. Ancak iki düşünür arasındaki temel fark; Aristuppus, bedensel hazlar tinsel hazlardan daha önemlidir ve hazzın niteliği önemsizdir derken Epicurus, bedensel hazzın değil tinsel hazzın sürekli olduğunu ve buna bedensel zevkler peşinde koşarak değil bilgelikle varılabileceğini savunur. $\mathrm{Bu}$ felsefenin takipçileri "endişelenme, mutlu ol" görüşünü savunurlar. Aristoteles (384-322 İÖ) için mutluluğun tanımı ise 'eudemonia' yani 'erdem ve akıl' ile sağlanan mutluluk ve iyi yaşamdır. 'Eudemonia' kişinin içsel benliğine doğrudur ve gerçek mutluluk ile ilişkilidir. Aristoteles erdemleri karakter ve entelektüel erdemler olarak ikiye ayırır. Entelektüel erdemlerin kaynağı öğretim iken karakter erdemlerinin kaynağı alıskanlıklarımızdır. Kişinin gerçek mutluluğa ulaşması bu erdemlerin gelişmesine bağlıdır. Aristoteles felsefesinin takipçisi “'Olabileceğin her şey ol ve bir fark yarat” der (Peterson ve ark. 2005). Aristoteles’in bakış açısıyla düşündügümüzde kişilerin yaşamlarında mutluluğa ulaşmalarını sağlamak için alışkanlık haline gelen rekreasyonel faaliyetlerin bilgi ve farkındalığının, erdeme dolayısıyla YD'na ulaşmak için büyük bir öneme sahip olduğu söylenebilir.

YD'nun farklı tanımları vardır. Shin ve Johnson (1978) bunu "bir kişinin yaşam kalitesinin seçtiği kriterlere göre küresel bir değerlendirmesi” olarak tanımlarken, Diener (1984) bunu öznel WB olarak tanımlamıştır. Diener (2000) başka bir çalışmada "insanların duygusal yaşamlarının bilişsel değerlendirmeleri”, Diener ve diğerleri (1985) “iyi yaşamın” önemli bileşenleri olarak tanımlarken, Pavot ve Diener (2018) YD'nu "kişilerin yaşamına ilişkin karar ve/veya his, yaşamına yönelik duygusal tutumu ve beklentilerini gerçekleştirme oranı" olarak tanımlamışlardır.

Tanımlarında görüldüğü gibi gerçekten benzer anlamlara sahipler ama her birinin konuşma dilinde kullanımları farklıdır.

\section{Yaşam Doyumunun Önemi}

Doyum kavramı, Yaşam Doyumu (YD), Boş Zaman Doyumu, Rol ve Evlilik Doyumu, İş Tatmini, Mesleki Doyum, Duygusal Doyum, Sosyal Doyum, Mesleki ve Ekonomik Memnuniyet gibi farklı kavramlarla bir araya geldiğinde pek çok anlama gelir. Doyum, beklentilerin gerçekleştirilme düzeyi olarak tanımlanabilir (Ardahan, 2018b). Bütün bu doyum kavramları; başkalarını etkiler ve onlardan etkilenir. Aralarında pozitif bir ilişki vardır. Aynı zamanda, tüm bu tatminler bireyin fiziksel, 
zihinsel, duygusal yaşamı/sağlı̆̆1, mesleki ve sosyal etkileşimi, WB, zindelik ve mutluluğunu etkiler ve bunlardan etkilenir. Bireysel YD üzerinde etkisi olan diğer parametreler şu şekilde sıralanabilir; a) karı/koca, partner, çocuklar, aile üyeleri, sosyal arkadaşlar, iş arkadaşları, akrabalar ve diğerleri ile anlamlı ilişki/etkileşime sahip olmak, b) tatmin edici düzeyde iş ve mesleki tatmine veya mesleki yaşamı desteklemek için yeterli kişisel ve ailevi gelire sahip olmak, tatmin edici bir mali doyuma sahip olmak, c) fiziksel, zihinsel, duygusal, sosyal, ruhsal ve entelektüel iyilik hali, d) tatmin edici bir komşuluk ve iyi donanımlı bir çevrede yaşamak, e) sosyal ve mesleki yaşamdan zevk almak, e) ev gibi maddi şeyler, hobi malzemeleri, araba/motosiklet, kıyafet vb. sahip olmak f) hobi ve boş zaman aktivitelerine katılmak, g) yüksek yaşam kalitesine sahip olmak, i) pozitif kişiliğe sahip olmak, j) tatmin edici cinsel yaşama sahip olmak, $\mathrm{k}$ ) çocuk isteyenlerin çocuk sahibi olmaları gibi unsurlara sahip olmak (Diener vd. 1985; Diener, 1984; Pavot ve Diener, 1993; Ardahan, 2018b). Bir şeye sahip olmak YD'nu arttırırken, bazen aynı şeye sahip olmak LS'yi azaltabilir. Örneğin, literatür maddi unsurların YD'nu olumlu etkilediğini söylese bile, düşük gelirli bir kişinin arabası olması arabanın maliyetlerini karşılama konusunda sıkıntı yaratabilir. Aşık olmak, evli/partner olmak YD'nu artturırken, bazen yalnız olmak YD'nu pozitif etkiler. YD'nu koşulların ve değişkenlerin nasıl etkileyeceği mevcut koşullara bağlıdır. Kişiden kişiye, zaman zaman kültürden kültüre değişebilir.

Tatmin olmuş ruh veya pozitif ruh mutludur ve/veya mutlu olmaya hazırdır ya da mutlu olmayı etkiler. Bu olumlu sağlık durumları için de söylenebilir. Mutlu ruh ve pozitif sağlık, genellikle daha yüksek YD'na sahip olmak için açık bir kapı olarak kabul edilebilir. Birçok araştırma sonucunda YD ile mutluluk, YD ve wellness arasında pozitif bir ilişki olduğu gösterilmiştir (Diener, 2000; Ibrahim ve Cordes, 2002; Ardahan, 2018b).

\section{Rekreasyonel Yaşamın Önemi}

Günlük yaşam üç bölüme ayrılabilir. Bunlar iş veya okul zamanı, uyku zamanı ve diğer zamanlardır. İş, okul ve uyku süresi yükümlülükler olarak tanımlanabilir. Diğer zamanlar ise rekreasyonel yaşam veya boş zaman hayatı ile kişisel bakım, çocuk bakımı, ev işi (temizlik, yemek pişirme), alışveriş gibi bazı sosyal yükümlülükleri içermektedir (Ardahan ve ark. 2016). Bazı araştırmacılar sosyal yükümlülükleri eğlence hayatı altında kategorize ederken, bazıları bunu bu şekilde ele almaz.

Rekreasyonel yaşam veya boş zaman; hayatı, bireylerin boş zamanlarında tek başlarına veya bir grup içerisinde özgür iradeleriyle yapabildikleri ve bunun sonucunda keyif aldıkları, fiziksel ve zihinsel olarak tazelenme, yenilenme ve eğlenceyi elde ettikleri keyifli aktivitelerin toplamı olarak tanımlanabilir. (Rossman ve Schlatter, 2000; Ibrahim ve Cordes, 2002). Rekreasyonel yaşam, Şekil1 'de gösterildiği gibi mutluluk, sağlık, esenlik ve YD elde etmek için aktif veya pasif katılım gerektirir. Pasif katılım izleyici olurken, aktif katılım bizatihi o etkinliği yapmayı tarif eder (Mull ve diğerleri, 2005). Futbol örnek alınırsa, oyuncular, hakemler ve teknik kadrolar aktif kattlımcilar olarak kabul edilebilir, futbol sahasındaki ve TV'deki seyirciler ise pasif katılımcılardır. Bazı boş zaman etkinlikleri, atölye çalışmaları gibi etkileşimli katılım gerektirir. Etkileşimli katılım, aktif katılım olarak kabul edilebilir (Ardahan ve ark. 2016). 
Ardahan, F. (2021). Aktif katılım bireylerin yaşam doyumunu nasıl etkiler? Journal of Human Sciences, 18(4), 592-615. doi:10.14687/jhs.v18i4.6175

Şekil-1/Figure-1: Katılım Tipi ve Seyirci Potansiyeli (Participant Type and Audience Potential)

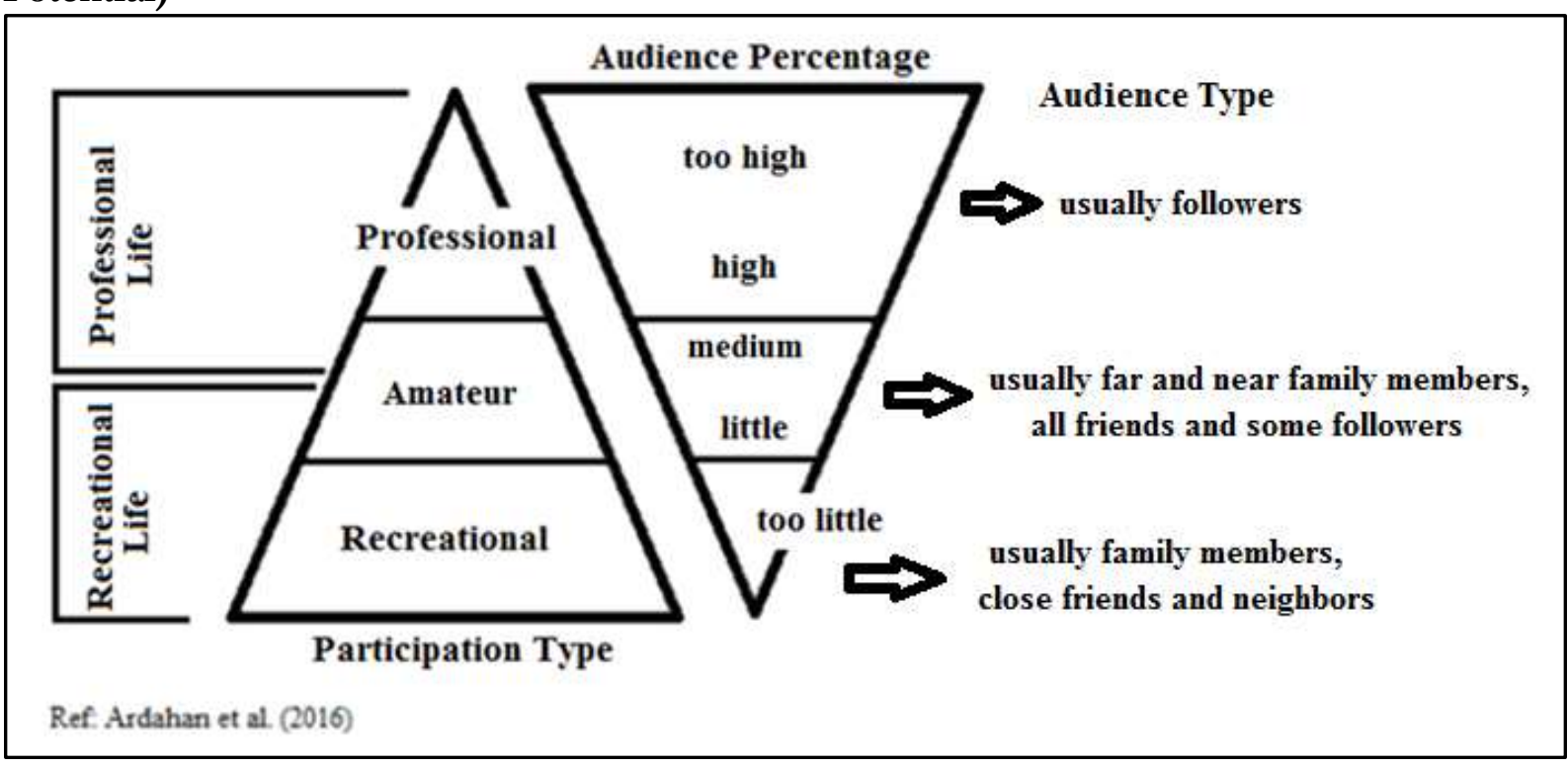

Günlük hayatta pasif katılım izleyici olurken; aktif katılım eğlence amaçlı, amatör veya profesyonel olabilir. Amatör katılımın bir kısmı rekreasyonel olarak kabul edilebilir ve geri kalanı profesyoneldir. Her türlü aktivitede seyirci potansiyeli profesyonel yaşama doğru yükselir. Eğlence yaşamında, amatör yaşamda izleyiciler genellikle aile üyeleri, yakın arkadaşlar ve komşulardır; kitle genellikle uzak ve yakın aile üyeleri, tüm arkadaşlar ve bazı takipçilerden oluşur, ancak profesyonel hayatta izleyiciler genellikle sosyal bir aidiyet yaratan takipçilerden oluşur.

Tüm boş zaman araştırmacıları, rekreasyon faaliyetlerine hem pasif hem de aktif katılımın YD üzerinde olumlu etkisi olduğu sonucuna varmıştır. Bu nedenle boş zamana katılım; sağlık, esenlik ve mutluluk için önemlidir. Boş zaman katılımının faydaları, daha yüksek YD'na açılan bir kapı olarak kabul edilebilir. Karşılaştırıldığında, aktif katılımın YD üzerinde pasif katılımdan potansiyel olarak daha yüksek olumlu etkisi vardır. Hem aktif hem de pasif katılımın, katılımsızlıktan daha fazla YD üzerinde olumlu etkisi vardır (Diener, 2000; Ardahan, 2012, 2016a, 2016b). Bu çalışmada, aktif katılım ve katılmamanın YD üzerindeki etkisi karşılaştırılmıştır.

Sebepler ve faydalar arasında karşılıklı bir ilişki vardır. Genellikle beklenen faydalar davranışımızı etkiler ve/veya tanımlar. Boş zaman katılımının faydaları; a) fiziksel ve zihinsel sağlığı geliştirir, b) bireyleri sosyalleştirir, c) özgüveni artırır, d) mevcut yetenekleri geliştirir, yeni yetenek ve beceriler kazandırır, e) bireysel sosyal kariyer firsatı elde eder, f) yaratıcı gücü geliştirir ve estetik algıyı deneyimleme firsatı yaratır, g) tatmin, mutluluk, zindelik ve refah verir, h) üretkenliği ve başarı algısını arttırır, i) sosyal dayanışma ve bütünleşmeyi sağlar, j) demokratik bir toplum oluşmasına izin verir, k) bireylerin ve toplumun yaşam kalitesini arttırır, l) sosyal sermayeyi artırır, m) bir yere veya bir gruba ait olmayı sağlar, n) kendini ifade etme ve kendini gerçekleştirme firsatı verir, o) hareketliliği artırır, p) ekonomi yaratır ve birçok sektör üzerinde olumlu etkiler yaratır, s) daha zengin bir aileye, arkadaşlığa ve komşuluk yaşantısına ve etkileşime sahip olmayı sağlar, t) entelektüel yaşam ve vizyon geliştirir, $\mathrm{u}$ ) sosyal ilişkileri geliştirir, dayanışma ve karş̧lıklılık sağlar, v) toplumun kültürel yaşamını zenginleştirir, y) her türlü bağımlılı̆̆1 azaltır, z) hastalığı önler, tedavi süresini kısaltır ve fiziksel ve zihinsel terapötik etki yaratır (Manfredo ve ark. 1996; Ibrahim ve Cordes, 2002; Ardahan vd. 2016).

Asıl soru, "tüm rekreasyonel katılımın YD üzerinde aynı etkiye sahip olup olmadığıdır?". Cevap "hayırdır". Etkisi kişiden kişsiye zamandan zamana değişebilir. Bu soru için Stebbins cevabı en iyisi olabilir. 
Stebbins (1992) rekreasyonel yaşamı gündelik boş zaman, proje temelli boş zaman ve ciddi boş zaman olarak üç kategoride sınıflandırmıştır. Gündelik boş zaman; genellikle hedonik, kısa süreli, parlak, rastgele ve organize edilmemiş, oyun, gevşeme, pasif eğlence, sosyal konuşma, duyusal uyarım gibi bunu yapmak veya katılmak için özel bir eğitim gerektirmeyen seçilmiş aktivitelerdir (Stebbins, 1997). Proje tabanlı boş zaman etkinlikleri, düzenli ancak seyrek, tek seferlik veya ara sıra katılım için iyi veya yarı donanımlı beceri ve bilgi gerektirir (sadece dügün töreninde dans etmek, sadece dini törenlerde şarkı söylemek, bahar şenliği, sanat festivali, spor etkinliklerine katılım gibi). Ciddi boş zaman aktiviteleri yaşam tarzıdır, aktivitede sebat etme, herhangi bir profesyonel beklenti olmaksızın boş zaman ve sosyal kariyer verme, iyi veya yüksek donanımlı beceri ve bilgi, hobici ve gönüllü katılım ve bazı özel faydaların gerçekleştirilmesini gerektirir (Stebbins, 1982, 2007). Ciddi boş zamanların YD üzerinde kalıcı olumlu etkisi vardır. Proje bazlı boş zaman aktiviteleri, yapıldığında YD üzerinde olumlu etkiye sahiptir, ancak düzenli tekrar gerektirir. Günlük boş zaman etkinlikleri hedoniktir ve YD üzerinde olumlu etkiye sahiptir.

Gündelik boş zaman aktiviteleri, Maslow İhtiyaç Teorisindeki Temel İhtiyaçlar gibi kabul edilebilir, YD üzerinde fayda ve olumlu etki elde etmek için tekrarı gereklidir. Pek çok bireyin rekreasyonel yaşamı bu düzeydedir. Maslow İhtiyaç Teorisinde proje tabanlı boş zaman Psikolojik/Orta İhtiyaçlar tupkı aidiyet ve sevgi ihtiyaçları gibidir. Bu, sıradan boş zamanlardan daha güçlü bir etkidir. Ancak YD üzerindeki en etkili etki, ciddi bir serbest zaman yaşamına sahip olmaktır. Bu bireyin kendini gerçekleştirme ihtiyacını karşılar.

\section{Motivasyon Teorileri ve YD Arasındaki İlişki}

Büyük ve en önemli soru "Davranışımızı ne belirler? Kararlarımız ve davranışlarımız YD’mumuzu nasıl etkiler?". Birçok araştırmacı bu soruyu kendi pencerelerinden yanıtlamıştır. Ancak bu soru henüz net bir şekilde cevaplanmış değildir. Kararlar hayatımızın yönünü, sahip olduğumuz ve terk ettiğimiz şeyleri tanımlar. Wymer vd.'nin (1996) cevabı "Değerler, Tutumlar ve Davranış ilişkisi modeli” kullanarak bu sorunun cevabını açıklamaktadır. Crandall (1980) davranışın kimlik ve koşullar arasındaki etkileşimin sonucu olduğunu savunmuş, Levy (1979) ise davranışın kimlik ile sosyal, ekonomik, komşuluk ve çevresel koşullar arasındaki etkileşimin sonucu olduğu savunmuştur. Örneğin, bir toplumda herkes bir şeyi kullanmayı reddederse, genellikle topluluk baskısı nedeniyle birisi bunu talep edemez veya bunun tersi de geçerlidir.

Bazı araştırmacılar bu soruyu cevaplamak için motivasyon teorileri kullanmıştır. Deci ve Ryan (1985), davranışımızın nedenini Öz Belirleme Teorisini (The Self-Determination Theory) kullanarak açıklamıştır. Bu teoride motivasyonun üç boyutu vardır: dişsal motivasyon, içsel motivasyon ve motivasyonsuzluk hali. Serbest zaman etkinliklerine katılım veya katılmama bu motivasyon türlerinin sonucu olabilir (Lii, 1999). Bunlara ek olarak Pintrich (2000), davranışımızın nedenini Başarı Hedef Teorisini (The Achievement Goal Theory) kullanarak açıklamaya çalışmışıtı. Bu teorinin iki tür amacı vardır. Birincisi Ego Merkezli yaklaşım, ikicisi, Görev Merkezli Yaklaşımdır. Ego Merkezli yaklaşımda; bireyin lider olma, başkalarıla rekabet etme, bir şeye/birine meydan okuma, tanınma arzusu, kendisiyle rekabet etme, kendine meydan okuma, yeni olma arzusu, onaylanma varken, Görev Merkezli Yaklaşımda ise sosyal duyarllık, başkalarına yardım etme, sosyal refah ve sosyal dayanışmaya sahip olma vardır (Roberts, 1993). Ego ve Göreve yönelik hedef genellikle bireyin kimliğini ve değerlerini tanımlar ve bireylerin YD’larını etkiler. Engeström vd. (2003) Aktivite Teorisini kullanarak davranışın nedenini açılamışlardır. Aktivite teorisine göre birey; nesne, içselleştirme/dışsallaştırma, arabuluculuk ve gelişime yönelik etkinlikler olmak üzere dört tür davranışa sahiptir. Aktivite teorisi genellikle fiziksel, zihinsel ve duygusal açıdan yeterli başarılı olmaya, bu şekilde yaşamaya ve yaşlanmaya odaklanır. Ve bu yeterliliklerin YD üzerinde olumlu etkisi vardır. Diğer bir motivasyon teorisi, Steg'in (2005), bir arabaya veya başka bir şeye sahip olmanın/kullanmanın araçsal, sembolik ve duygusal motiflerini ilişkilendirildiği Araç Kullanım Motivasyonu Teorisidir (Motivation for Vehicle Use Theory). Son olarak ana soruyu cevaplamak için kullanılan teori, Maslow tarafindan geliştirilen İhtiyaç Teorisidir (Ibrahim ve Cordes, 2002). Bu teoride, bireyleri tatmin etmek için motive 
Ardahan, F. (2021). Aktif katılım bireylerin yaşam doyumunu nasıl etkiler? Journal of Human Sciences, 18(4), 592-615. doi:10.14687/jhs.v18i4.6175

etmenin gerekli olduğu ve tatmin olduğunda doyum sağladığı sonucuna varılır. Bu teori beş aşamalı ihtiyaçlar ve boyutlar hiyerarşisine sahiptir. Bunlar;

- Fiziksel Boyut, Fizyolojik İhtiyaçlar (giyim, yiyecek, barınma, cinsiyet vb.),

- Çevresel boyut, Güvenlik İhtiyaçları (kazalara / hastalı̆ga karşı, kişisel, duygusal ve finansal güvenlik, sağlıklı ve refah, ihtiyaçlar),

- Sosyokültürel Boyut, Aidiyet ve Sevgi İhtiyaçları (arkadaşlık, yakınlık, aile, bir gruba, organizasyon, ulus, alt kültür),

- Duygusal Boyut, Benlik Saygısı İhtiyaçları,

- Entelektüel ve Manevi Boyutlar, Kendini Gerçekleştirme ve Kendini Aşma İhtiyaçları.

Rekreasyon, Maslow'un ihtiyaçlar hiyerarşisinde ilk aşamadan yukarıya doğru her aşamada gereksinim duyulan bir ihtiyaçtır. Yiyecek ve içecek olarak Fizyolojik İhtiyaçlar, her türlü güvenlik gereksiniminin tanımlandığı Güvenlik İhtiyaçları, aynı zamanda tüm bu ihtiyaçların karşılanması yemek yemek, sağlık için egzersiz yapmak bir boş zaman aktivitesi olabilir. Bir gruba, aileye veya kuruluşa ait olmak bir ihtiyaçtır ve boş zaman aktivitelerine katılmak bu değişimi ve doyumu sağlar/yaratır. Benlik Saygısı İhtiyaçlanı, Kendini Gerçekleştirme ve Kendini Aşma İhtiyaçları üst düzey ihtiyaçlardır ve bu ihtiyaçları karşılamak için bir rekreasyonel faaliyete katıldığında, normal ciddi boş zaman faaliyetidir ve daha yüksek düzeyde tatmin sağlar/yaratır.

\section{Demografik Değişkenler ve YD}

Birçok araştırmac1, demografik değişkenlerin YD'nu nasıl etkilediğini incelemiştir. Gelirin YD üzerinde olumlu etkisi olduğu ve aralarında pozitif bir korelasyon olduğu açıktır. Karşılaştırıldığında, finansal refah ve çalışma ile ilgili diğer memnuniyetlere bağlı olarak, çalışanların emekli ve işsizlere göre daha yüksek YD’na sahip olduğu söylenebilir (Diener, 1984, 2000; Diener ve ark. 1985; Helliwell, 2003; Bjørnskov ve ark.2008; Ardahan, 2012, 2016b, 2018b, 2018c).

Birçok evli birey tercih ettiği serbest zaman aktivitesine tek başına katulmak istese de anlamlı ve doyumlu evlilik çiftlerin rekreasyon yaşamını olumlu yönde desteklemektedir. Buna ek olarak evlilik, çocuk sahibi çiftlere firsat, sosyal destek sağlar, kolektivizm yaratır (en küçük ekip faaliyeti) ve bunlar da YD'nu artırır veya olumlu etkiler (Diener ve diğerleri 2000; Helliwell, 2003; Bjørnskov ve diğerleri 2008; Ardahan, 2012, 2016b, 2018b, 2018c). Eğitim, dağcllikta olduğu gibi trrmanış olarak kabul edilebilir. Hava (zihniniz) açıksa ve yeterince yüksek rakımdaysanız (iyi eğitim almıssanız) uzakları görebilirsiniz. Farkındalık düzeyini, uzağı görme ve problem çözme yeteneğini artırır ve YD üzerinde olumlu etkisi vardır (Diener, 1984, 2000; Diener vd. 1985; Helliwell, 2003; Bjørnskov vd. 2008; Ardahan, 2012, 2016b, 2018b, 2018c). Diener ve Diener (1995) kadın ve erkeklerin çok yakın YD'na sahip oldukları sonucuna varmış olsalar da, son araşturmalar kadınların YD'larının Türkiye dahil birçok ülkede daha yüksek olduğunu göstermektedir (Ardahan, 2012, 2016b, 2018b, 2018c).

Yaş, serbest zaman faaliyetleri ve YD'nun önemli diğer belirleyicisidir. Gençler genellikle serbest zaman aktivitelerini tercih ederken, daha yüksek fiziksel performansa ihtiyaç duyar, daha yüksek risk alır, bu yaşlanmayla azalır. Gençler gelecek konusunda tereddüt etmez; çalışmadan gelirleri ve daha fazla fiziksel enerjileri, daha yüksek özgüvenleri ve YD’ları vardır. Daha sonra eğitim hayatlarını bitirdiklerinde orta yaşa kadar profesyonel ve sosyal kariyer (evlilik, çocuk, ev satın alma, araba vb.) için mücadele ederler. Bu yaştan sonra genellikle birçok hedefin farkına varırlar, mesleki ve sosyal kariyerlerini netleştirirler ve genellikle kendilerini ihmal ederler, daha sonra kendi hayatlarına geri dönerler ve kendilerini yüksek oranda gerçekleştirme ile rekreasyonel hayatlarını zenginleştirirler. Genellikle yaş arttıkça, bireylerin profesyonel kariyerleri ilerler, dolayısıyla bireyler daha yüksek gelir, ekonomik refah elde eder ve bu da daha yüksek YD’na ulaşmalanna yol açar (Ardahan, 2018b). 
Ardahan, F. (2021). Aktif katılım bireylerin yaşam doyumunu nasıl etkiler? Journal of Human Sciences, 18(4), 592-615. doi:10.14687/jhs.v18i4.6175

\section{Yöntem}

$\mathrm{Bu}$ araştırmanın temel amac1, bazı rekreasyonel faaliyetlere aktif katılımı olan bireylerin, aynı rekreasyonel faaliyetlere aktif katılımı olmayan bireylerin yaş, cinsiyet, medeni durum, kişisel gelir, istihdam türü, eğitim düzeyi ve rekreasyonel faaliyetler gibi bazı demografik değisskenler açısından Yaşam Doyumu (YD) düzeylerini karşılaştırmaktır.

Araştırmanın örneklemini 4214 erkek ve 1287 kadın toplam 5501 kişi oluşturmaktadır. Veriler Rekreasyonel faaliyetler ve YD'na odaklanan on üç farklı araştırmadan alınmıştır. Bu araştırmaların dokuzu aktif katılım gerektiren; Bisiklet festivalleri (Ardahan ve Lapa Yerlisu, 2011), Dağcllık / kaya tırmanış1 yapanlar (Ardahan, 2012), Trekking / doğa yürüyüşü yapanlar (Ardahan, 2012), Avc1lık yapanlar (Ardahan ve Turgut, 2013), Balıkçılık yapanlar (Ardahan ve Turgut, 2013), Rekreasyonel amaçlı bisiklet kullananlar (Ardahan ve Mert, 2014), Rekreasyonel amaçlı motosiklet kullananlar (Ardahan ve Güleç, 2017), Bir sivil toplum kuruluşunda gönüllü olanlar (Ardahan, 2016b), ve Rekreasyonel korolarda korist olarak şark1 söyleyen (Ardahan, 2016b) bireylerden ve dördü de hiçbir sivil toplum kuruluşunda gönüllü olarak rol almamıss (Ardahan, 2018c), açık alan etkinliklerine hiç katılmamış (Ardahan, 2012), hiç avcılık ve balıkçılık yapmamış (Ardahan ve Turgut, 2013), hiçbir koroda bulunmamış (Ardahan, 2016b) kişilerden oluşmaktadır.

Her veri setinden demografik değişkenler; cinsiyet, medeni durum, eğitim seviyesi, yaş, istihdam türü olduğu gibi alınmış, ancak resmi asgari ücrete ilişkin kişisel aylık gelir üzerinde yapılan bazı düzenlemeler ve 2018 ABD \$ baz yılı 100 olarak kabul edilip hesaplanmıştr.

Verilerin analizinde betimsel istatistiklerin yanı sira Independent Sample t-testi ve ANOVA testi kullanılmış, farklılıkların nedenini belirlemek için LSD testi uygulanmıştır. Tüm sonuçlar 0.05 anlamlı seviyelerde analiz edilmiştir.

\section{Bulgular}

Bu araştırmanın demografik değişkenleri Tablo-1'de verilmiştir. Tablo-1'de görüldüğü gibi, katılımcıların çoğunluğu erkek, bekar, iyi eğitimli, 44 yaşında ve daha küçük, aylık $700 €$ civarında kişisel gelire sahip, kamu veya özel sektörde çalışan veya kendi adına çalışan, açık alan aktivitelerinden birinde aktif katılan veya bir STK veya koro şarkıcılarında gönüllü olan bireylerden oluşmaktadır.

Tablo-1: Demografik Değişkenler

\begin{tabular}{|c|c|c|c|c|c|}
\hline Demografik Değişkenler & $\mathrm{n}$ & $\%$ & Demografik Değişkenler & n & $\%$ \\
\hline Dağcılık / Kaya Tirmanışı Yapanlar & 426 & 7,70 & Özel Sektör & 1783 & 32,40 \\
\hline Bisiklet Festivaline Katılanlar & 373 & 6,80 & Kamu Sektörü & 925 & 16,80 \\
\hline Trekking / Doğa Yürüyüşü Yapanlar & 382 & 6,90 & Kendi İşi/Serbest Meslek & 1221 & 22,20 \\
\hline Aç1k Alan aktivitesine katılmayanlar & 538 & 9,80 & Ev Kadinı & 140 & 2,50 \\
\hline Avcılik Yapanlar & 187 & 3,40 & Öğrenci & 847 & 15,40 \\
\hline Balıkçılık Yapanlar & 367 & 6,70 & Emekli & 381 & 6,90 \\
\hline Avcllık ve Balıkçılık Yapmayanlar & 324 & 5,90 & İssiz & 204 & 3,70 \\
\hline Rekreasyonel Motor Kullaniciları & 947 & 17,20 & $350 €$ ve alt1 & 1287 & 23,40 \\
\hline Herhangi bir STK'da gönüllülük yapanlar & 208 & 3,80 & $351-700 €$ & 1529 & 27,80 \\
\hline Asla Gönüllü Olmayanlar & 138 & 2,50 & $701-1050 €$ & 1189 & 21,60 \\
\hline Rekreasyonel Korolarda Korist Olanlar & 633 & 11,50 & $1051 €$ ve üstü & 1496 & 27,20 \\
\hline Herhangi bir koroda görev almayanlar & 296 & 5,40 & 24 yaş ve altı & 1116 & 20,30 \\
\hline Rekreasyonel Bisiklet Kullananlar & 682 & 12,40 & $25-34$ yaş & 1649 & 30,00 \\
\hline Erkek & 4214 & 76,60 & $35-44$ yaş & 1209 & 22,00 \\
\hline Kadin & 1287 & 23,40 & $45-54$ yaş & 877 & 15,90 \\
\hline$\overline{\text { Evli }}$ & 2262 & 41,10 & 55 yaş ve üstü & 650 & 11,80 \\
\hline Bekâr & 3239 & 58,90 & Lise dengi ve altı & 1526 & 27,70 \\
\hline Aktif faaliyetlerde katılan bireyler & 4205 & 76,40 & Üniversite ve üstü & 3975 & 72,30 \\
\hline Aktif Katılımı olmayan bireyler & 1296 & 23,60 & Toplam & 5501 & 100,00 \\
\hline
\end{tabular}

Not=1€=3.58 TL 1 Mayis 2017 
Ardahan, F. (2021). Aktif katılım bireylerin yaşam doyumunu nasıl etkiler? Journal of Human Sciences, 18(4), 592-615. doi: $10.14687 /$ jhs.v18i4.6175

Kattlımcıların YD düzeyi ve YD düzeyinin demografik değişkenlere göre karşılaştırılması Tablo-2'de verilmiştir. Tablo-2'de görüldüğü gibi, aktif serbest zaman faaliyetlerine katulmak bireylerin YD düzeyini arttırmaktadır. Korolara katılan, Trekking/Doğa Yürüyüşü yapan, Rekreasyonel olarak Motor Kullanan, Dağcılık/Kaya Tırmanışı yapan, Rekreasyonel olarak Bisiklet binen, Avcıllk yapan, Balıkçılık yapan, Bisiklet Festivallerine katılan, gönüllülük yapan bireylerin YD’ları, bu tür serbest zaman aktivitelerine katılmayanlarla karşılaştırıldığında istatistiksel olarak aktif katılım lehine anlamlı pozitif fark yaratmaktadır. En yüksek YD’na sahip bireyler bir STK'da gönüllü olarak rol alanlarındır. Buna ek olarak, kadınlar erkeklerden daha yüksek YD'na sahip, evliler bekarlardan daha yüksek YD'na sahip, serbest meslek sahibi, emekli bireyler ve kamu sektörü çalışanları diğerlerinden daha yüksek YD'na sahip, yüksek personel aylık geliri olanlar daha yüksek YD'na sahip, daha yüksek yaştaki bireyler daha yüksek YD sahiptirler. Bunların aksine, eğitim seviyesi daha yüksek/daha düşük YD'na sahip olmak için bir neden değildir.

Tablo-2: Yaşam Doyumunun Etkinliklere Aktif Katılma/Katılmama Durumunun Çeşitli

Değişkenlere Göre Karşılaştırılması

\begin{tabular}{|c|c|c|c|}
\hline Demografik Değişkenler & Mean \pm SD & Demografik Değişkenler & Mean \pm SD \\
\hline Trekking / Doğa Yürüyüuşü Yapanlar & $3,38 \pm 0,759$ & Avcilik Yapanlar & $3,38 \pm 0,673$ \\
\hline Rekreasyonel Motor Kullanicilar1 & $3,38 \pm 0,841$ & Balıkçllık Yapanlar & $3,38 \pm 0,707$ \\
\hline Dağcllık / Kaya Tirmanışı Yapanlar & $3,28 \pm 0,836$ & Avcllık ve Balıkçlık Yapmayanlar & $2,94 \pm 0,929$ \\
\hline Rekreasyonel Bisiklet Kullananlar & $3,24 \pm 0,728$ & Kendi İşi/Serbest Meslek & $3,39 \pm 0,808$ \\
\hline Bisiklet Festivaline Katılanlar & $3,16 \pm 0,823$ & Emekli & $3,34 \pm 0,770$ \\
\hline Açık Alan aktivitesine katılmayanlar & $3,08 \pm 0,925$ & Kamu Sektörü & $3,33 \pm 0,774$ \\
\hline Herhangi bir STK'da gönüllülük yapanlar & $3,53 \pm 0,506$ & Öğrenci & $3,24 \pm 0,824$ \\
\hline Asla Gönüllü Olmayanlar & $3,27 \pm 0,997$ & Özel Sektör & $3,23 \pm 0,829$ \\
\hline Rekreasyonel Korolarda Korist Olanlar & $3,45 \pm 0,822$ & Ev Hanımı & $3,20 \pm 0,961$ \\
\hline Herhangi bir koroda görev almayanlar & $3,11 \pm 0,868$ & İşsiz & $2,94 \pm 1,031$ \\
\hline Erkek & $3,25 \pm 0,827$ & $350 €$ ve altı & $3,08 \pm 0,875$ \\
\hline Kadın & $3,36 \pm 0,824$ & $351-700 €$ & $3,29 \pm 0,814$ \\
\hline Evli & $3,34 \pm 0,793$ & $701-1050 €$ & $3,31 \pm 0,847$ \\
\hline Bekâr & $3,24 \pm 0,848$ & $1051 €$ ve üstü & $3,41 \pm 0,748$ \\
\hline Aktif faaliyetlerde katılan bireyler & $3,34 \pm 0,784$ & 24 yaş ve altı & $3,21 \pm 0,883$ \\
\hline Aktif Katllimı olmayan bireyler & $3,07 \pm 0,925$ & $25-34$ yaş & $3,21 \pm 0,821$ \\
\hline Lise dengi ve altı & $3,27 \pm 0,849$ & $35-44$ yaş & $3,29 \pm 0,829$ \\
\hline Üniversite ve üstü & $3,28 \pm 0,819$ & $45-54$ yaş & $3,35 \pm 0,776$ \\
\hline İstatistiki Karşılaştırmalar & $\mathbf{t}$ & 55 yaş ve üstü & $3,45 \pm 0,776$ \\
\hline Cinsiyet & $-4,176^{*}$ & İstatistiki Karş1laştırmalar & $\mathbf{F}$ \\
\hline Medeni Durum & $4,304^{*}$ & Rekreasyonel Aktiviteye Göre & $15,426^{*}$ \\
\hline Eğitim Düzeyi & $-0,257$ & Yaşa Göre & $13,361 *$ \\
\hline Aktif Katılim & $9,558^{*}$ & Kişisel Gelir & $39,738^{*}$ \\
\hline$* \mathrm{p}<0.05$ & & Çalışılan Yer & $11,776^{*}$ \\
\hline
\end{tabular}

Rekreasyonel etkinliklere aktif katılanlar ile bu tür rekreasyonel aktivitelere katulmayanların YD düzeylerinin Eğitim Düzeyi, Cinsiyet, Medeni Durum, Yaş, Kişisel Gelir, İstihdam Türü ve rekreasyonel aktivite türlerine göre karşılaştırılması Tablo-3'te verilmiştir. Tablo-3'te görüldüğü gibi; aktif katılımcıların YD'lanı ve katılımcı olmayanların YD'larının tüm karşılaştırmasında, aktif katılımcılar lehine istatistiksel olarak anlamlı fark bulunmuştur.

Aktif katulımda iki farklı eğitim seviyesi arasında YD açısından istatistiksel olarak anlamlı bir fark bulunmazken, listelenen rekreasyonel aktivitelere katılmayan bireylerin eğitim düzeyine göre üniversite eğitimi olanların lehine istatistiksel olarak anlamlı bir fark vardır. 
Ardahan, F. (2021). Aktif katılım bireylerin yaşam doyumunu nasıl etkiler? Journal of Human Sciences, 18(4), 592-615. doi: $10.14687 /$ jhs.v18i4.6175

Cinsiyete göre YD seviyesi karşılaştırıldığında, listelenen rekreasyonel aktivitelere aktif katılanlarda ve katılmayanlarda kadınların lehine istatistiksel olarak anlamlı pozitif fark vardır.

Evlilik, en küçük ekip ve duygusal işbirliğidir. Aktif katıllımda evli olanlar lehine YD açısından pozitif istatistiksel olarak anlaml fark varken, katılmayanlarda evli ve bekarlar arasında YD açısından istatistiksel olarak anlamlı bir fark yoktur.

Listelenen rekreasyonel aktivitelere aktif katılan ve bu tür aktivitelere katılmayan bireylerin YD’ları orta yaşın üstündeki bireyler ve daha yüksek kişisel gelire sahip bireylerin lehine istatistiksel olarak anlamlı pozitif fark vardır.

Listelenen rekreasyonel aktivitelere aktif katılan işsiz bireylerin YD’ları diğer meslek gruplarına göre istatistiki olarak daha düşüktür. Listelenen rekreasyonel aktivitelere katılmayan bireylerle işsiz olanlar ve ev hanımlarının YD’ları diğer gruplara göre istatistiksel olarak anlamlı derecede daha düşüktür.

Tablo-3: Listelenen Aktivitelere Aktif Katılan ve Hiç Katılmayan Bireylerin YD’larının Eğitim seviyesi, Cinsiyet, Medeni Durumu, Yaş, Kişisel Gelir, Çalışma Biçimi ve Rekreasyonel Aktivite Türüne Göre Karşılaştırılması

\begin{tabular}{|c|c|c|c|c|c|}
\hline \multirow[t]{2}{*}{ Demografik Değişken } & \multicolumn{2}{|c|}{ Aktif Kat1lım } & \multicolumn{2}{|c|}{ Katılmama } & \multirow{2}{*}{$\begin{array}{c}\text { Karşılaş̧tırma } \\
\text { t/F }\end{array}$} \\
\hline & $\mathbf{n}$ & Mean \pm SD & $\mathbf{n}$ & Mean $\pm S D$ & \\
\hline Lise dengi ve alt1 & 1349 & $3,33 \pm 0,828$ & 177 & $2,90 \pm 0,907$ & 6,384* \\
\hline Üniversite ve üstü & 2856 & $3,35 \pm 0,762$ & 1119 & $3,10 \pm 0,926$ & $8,120 *$ \\
\hline Eğitime göre karşılaştırma (t) & & $-1,048$ & & $-2,716^{*}$ & \\
\hline Erkek & 3382 & $3,32 \pm 0,785$ & 832 & $2,97 \pm 0,934$ & 9,464* \\
\hline Kadın & 823 & $3,44 \pm 0,773$ & 464 & $3,22 \pm 0,891$ & $4,437^{*}$ \\
\hline Cinsiyete göre karşılaştırma (t) & & $-4,054 *$ & & $-4,439 *$ & \\
\hline$\overline{\text { Evli }}$ & 1885 & $3,38 \pm 0,771$ & 377 & $3,13 \pm 0,867$ & $5,115^{*}$ \\
\hline Bekâr & 2320 & $3,32 \pm 0,793$ & 919 & $3,05 \pm 0,948$ & $7,599 *$ \\
\hline Medeni duruma göre karşılaştırma (t) & & $2,514 *$ & & 1,480 & \\
\hline 24 yaş ve altı & 657 & $3,29 \pm 0,819$ & 459 & $3,10 \pm 0,956$ & $3,363 *$ \\
\hline $25-34$ yaş & 1266 & $3,29 \pm 0,763$ & 383 & $2,97 \pm 0,952$ & $5,879 *$ \\
\hline $35-44$ yaş & 1027 & $3,33 \pm 0,798$ & 182 & $3,06 \pm 0,959$ & $3,535^{*}$ \\
\hline $45-54$ yaş & 687 & $3,43 \pm 0,763$ & 190 & $3,07 \pm 0,758$ & $5,740 *$ \\
\hline 55 yaş ve üstü & 568 & $3,46 \pm 0,768$ & 82 & $3,39 \pm 0,829$ & 0,843 \\
\hline Yaşa göre karşılaştırma $(\mathrm{F})$ & & $7,937 *$ & & $3,631 *$ & \\
\hline $350 €$ ve altt & 802 & $3,16 \pm 0,811$ & 485 & $2,94 \pm 0,954$ & $4,349 *$ \\
\hline $351-700 €$ & 1191 & $3,35 \pm 0,791$ & 338 & $3,08 \pm 0,862$ & $5,404 *$ \\
\hline $701-1050 €$ & 943 & $3,37 \pm 0,792$ & 246 & $3,09 \pm 1,004$ & $4,131 *$ \\
\hline $1051 €$ ve üstü & 1269 & $3,43 \pm 0,735$ & 227 & $3,33 \pm 0,808$ & $1,785 *$ \\
\hline Kişisel aylık gelire göre karşılaştırma $(\mathrm{F})$ & & $19,685^{*}$ & & $9,289 *$ & \\
\hline Özel Sektör & 1400 & $3,27 \pm 0,791$ & 383 & $3,06 \pm 0,936$ & $4,107 *$ \\
\hline Kamu Sektörü & 706 & $3,39 \pm 0,718$ & 219 & $3,12 \pm 0,901$ & $4,135^{*}$ \\
\hline Kendi İşi/Serbest Meslek & 1074 & $3,41 \pm 0,780$ & 147 & $3,18 \pm 0,969$ & $2,753 *$ \\
\hline Ev Hanımı & 82 & $3,49 \pm 0,758$ & 58 & $2,79 \pm 1,067$ & $4,297 *$ \\
\hline Öğrenci & 497 & $3,29 \pm 0,787$ & 350 & $3,19 \pm 0,871$ & $1,752 *$ \\
\hline Emekli & 297 & $3,42 \pm 0,795$ & 84 & $3,07 \pm 0,602$ & $4,137 *$ \\
\hline İşsiz & 149 & $3,19 \pm 0,932$ & 55 & $2,24 \pm 0,968$ & $6,313 *$ \\
\hline Çalışılan Yere Göre Karşılaştırma (F) & & $5,961 *$ & & $10,064 *$ & \\
\hline Herhangi bir açık alan etkinliğine katılanlar & 2810 & $3,30 \pm 0,804$ & 538 & $3,08 \pm 0,925$ & $5,206^{*}$ \\
\hline Avcllık veya Balıcçlık yapanlar & 554 & $3,38 \pm 0,695$ & 324 & $2,94 \pm 0,929$ & $7,400 *$ \\
\hline STK'da gönüllü olanlar & 208 & $3,53 \pm 0,506$ & 138 & $3,27 \pm 0,997$ & $2,808 *$ \\
\hline Rekreasyonel korolarda korist olanlar & 633 & $3,45 \pm 0,822$ & 296 & $3,11 \pm 0,868$ & $5,654 *$ \\
\hline
\end{tabular}
* $\mathrm{p}<0.05$ 
Ardahan, F. (2021). Aktif katılım bireylerin yaşam doyumunu nasıl etkiler? Journal of Human Sciences, 18(4), 592-615. doi:10.14687/jhs.v18i4.6175

\section{Tartışma}

$\mathrm{Bu}$ çalsşmada, bazı rekreasyonel etkinliklere aktif olarak katılan ve bu tür etkinliklere katılmayan bireylerin YD’larının; yaş, cinsiyet, medeni durum, kişisel gelir, istihdam türü, eğitim düzeyi ve rekreasyonel etkinliklere göre karşılaştırması yapılmıştır.

Sonuçlar, rekreasyonel faaliyetlere aktif katılımın YD üzerinde olumlu etkisinin olduğunu göstermektedir. Türkiye'de ve diğer ülkelerde yapılan birçok çalışma ve rekreasyon teorileri bu sonucu doğrular/destekler niteliktedir. Bu çalışmada dağcllık, spor tırmanışı, avcılık, rekreasyonel bisiklet ve motor kullanımı, doğa yürüyüşü/trekking gibi aktif katılımlı rekreasyonel aktiviteler benzer nitelikte aktiviteler olarak kabul edilir ve balık tutma, gönüllülük, bisiklet festivaline katılma, rekreasyon korolarında korist olma farklı karakter, farklı fiziksel ve zihinsel yetenekler gerektirse de bu tür aktivitelere aktif katılan ve katılımcı olmayanlarla karşılaştırıldığında her biri YD üzerinde olumlu etki yaratmaktadır (Pavot ve Diener, 1993; Manfredo ve diğerleri 1996; Diener, 1984, 2000; Ibrahim ve Cordes, 2002; Ardahan, 2012, 2016a, 2016b). Motivasyon teorileri de rekreasyonel etkinliklere aktif katılımın YD üzerindeki olumlu etkisini desteklemekte ve önermektedir (Deci ve Ryan, 1985; Diener ve diğerleri 1985; Roberts, 1993; Diener ve Diener; 1995; Lii, 1999; Pintrich, 2000; Ibrahim ve Cordes, 2002; Engeström ve diğerleri. 2003; Helliwell, 2003; Steg, 2005; Ardahan, 2012, 2016a, 2016b; Ardahan vd. 2016).

Birçok çalışmada rekreasyonel etkinlik talebinin demografik değişkenlere göre değişebileceği (Ardahan, 2012), ancak YD’nun demografik değişkenlere göre değişmeyebileceği bulunmuştur. Ardahan'in (2016a, 2016b, 2018b) çalışmalarında, katılımcıların her iki cinsiyette de aktif ciddi boş zaman yaşamına sahip olduğu görülmüştür. YD; cinsiyete göre karşılaştırıldı̆̆ında, aktif katılımcılarda ve katılımcı olmayanlar arasında kadınlar lehine, aktif katılımcının erkekleri ile katılımcı olmayanların erkekleri arasında aktif erkekler lehine istatistiksel olarak anlamlı farkllıklar vardır. Aktif katılımciların kadınları ve katılmayanların kadınları karşılaştııldığında, aktif kadınlar lehine istatistiki olarak anlamlı farklılık vardır. Kadınlar daha yüksek YD’na sahip oldukları için şanslılar veya başka bir deyişle hayatı daha keyifli hale getirebilmenin altlkklarını yaratabilmekteler, içinde oldukları durumları erkeklerden daha iyi yönetebilmektedirler (Ardahan, 2012, 2016b, 2018b, 2018c). Diener ve Diener (1995) kadın ve erkeklerin çok yakın YD'na sahip oldukları sonucuna varsa bile, son araştırmalar birçok ülkede kadınların daha yüksek YD'na sahip olduğunu göstermektedir.

Gelir, YD'nun en temel olumlu belirleyicilerinden biridir (Diener ve ark. 1985) ve birçok çalışmada, gelir arttığında YD seviyesinin arttı̆̆ bulunmuştur (White, 1975; Scott ve Munson, 1994). Lee ve diğerleri. (2001) ve Solop ve ark. (2001) eğitim seviyesi, kişisel gelir ve istihdam durumundaki ilerlemenin rekreasyon talebi üzerinde olumlu etkisi olduğu sonucuna varmıştır. Bu çalışmanın sonuçları YD'nun rekreasyonel aktivitelere katılmayı isteyenlerin veya katılanların lehinde artış gösterdiği/göstereceği bilimsel gerçeğini desteklemektedir. Aktif katılımcı grubunda ve katılımc1 olmayanlarda gelir arttığında YD da artar. Bu sonuca ek olarak, finansal refah ve aktif kattlımcılarda ve katılımcı olmayanlarda çalısmaktan kaynaklanan diğer memnuniyetlere bağlı olarak, çalışan bireylerin işsizlere göre daha yüksek YD'na sahip olduklan bulunmuştur. Ancak tüm istihdam türlerinde aktif katılımcının YD seviyesi, katılımcı olmayanlara göre daha yüksektir. Diener (1984, 2000), Diener ve ark. (1985), Helliwell (2003), Bjørnskov ve diğerleri. (2008) ve Ardahan (2012, 2016b, 2018b, 2018c) bu sonuçları desteklemektedir.

Eğitim tıpkı bir merdiven gibidir ve mesleki, rekreasyonel ve sosyal bilgelik verir (Ardahan vd. 2016, Ardahan vd. 2017) ve farkındalık düzeyini, uzağ1 görme yeteneğini ve problem çözme becerisini ve YD'nu artırır (Beyaz , 1975; Diener, 1984, 2000; Diener ve diğerleri 1985; Lee ve diğerleri 2001; Solop ve diğerleri 2001; Helliwell, 2003; Bjørnskov ve diğerleri 2008; Ardahan, 2012, 2016b, 2018b, 2018c). Bu çalışmalarda verilen sonuçlar, mevcut çalışmanın sonucunu desteklemektedir. Aktif katılımcılar ve katılımcı olmayanlarla karşılaştırıldığında, her iki eğitim düzeyinde de aktif katılımın katılımcı olmayanlara göre istatistiksel olarak anlamlı düzeyde daha yüksek YD verdiği görülmüştür. Buna ek olarak, eğitim düzeyi karşılaştırıldığında, aktif katılımcı grubunda istatistiksel olarak anlamlı bir fark bulunmazken, katılımcı olmayan gruptaki farklılıklarda istatistiksel olarak anlamlı farklıliklar bulunmaktadır. Bu sonuçlar eğitimin YD düzeyi üzerinde olumlu etkisi olduğunu göstermektedir. 
Rekreasyon literatüründe evlilik/çift-partner yaşamı, aktif katılım gerektiren serbest zaman etkinlikleri için kısıt olarak kabul edilmemektedir (Ardahan ve diğerleri 2016, Ardahan ve diğerleri 2017, İbrahim ve Cordes, 2002). Hatta tam tersine anlaml ve doyumlu bir evlilik veya çift-partner yaşamına sahip olmak aktif katılımı desteklemektedir. $\mathrm{Bu}$ sonuç, bu çalışmanın sonuçlarıyla örtüşmektedir. Karşılaştırıldığında; aktif katılımcılar grubunda evli katılımcılar bekarlara göre daha yüksek YD'na ve evli olanlar lehine istatistiksel olarak anlamlı farklılıklara sahipken, katıllımcı olmayan gruplarda evli katılımcılar bekarlara göre daha yüksek YD'na sahiptir ve bekarlar ile evli olanlar arasında istatistiksel olarak anlamlı bir fark yoktur.

\section{Sonuç}

Bulgular, kadın, evli, çalışan, orta yaşlı ve/veya daha büyük olmanın, aktif serbest yaşama sahip olmanın ve daha yüksek kişisel gelire sahip olmanın istatistiksel olarak anlamlı düzeyde daha yüksek YD ile ilişkili olduğunu göstermektedir. Buna ek olarak, aktif serbest yaşama sahip olmak, bireylerin YD düzeyi üzerinde olumlu bir etkiye yol açmaktadır. Her bir demografik değişkenle karşılaştırıldığında, bazı rekreasyonel faaliyetlerin aktif katılımcıları olan ve aynı faaliyetlere katılmayan bireyler arasında YD seviyeleri arasında istatistiksel olarak anlamlı farklılıklar vardır.

Sonuç olarak, daha yüksek YD seviyesine sahip olmak için, aktif serbest zaman hayatına veya herhangi bir rekreasyonel aktiviteye aktif katılımın gerekli olduğu sonucuna varılabilir. Bunun için, eğitimin her aşamasında bireyler nasıl aktif bir serbest zaman hayatına sahip olacakları, aktif yaşamın avantajlarının neler olduğu konusunda eğitilmeli ve motive edilmelidir. Buna ilave olarak; içinde yaşadığımız yerler kentsel tasarım ve altyapı yatırımları açısından o kentte yaşayanların rekreasyonel katılımlarını desteklemeli ve motive etmelidir.

YD üzerindeki etkilerini ortaya çıkarmak için daha ileriki çalışmalarda aktif katulım ve pasif katılımın araştırılması önemlidir ve tavsiye edilir. Kamu ve özel teşebbüsler, belediyeler, üniversiteler, sivil toplum kuruluşları, tiyatrolar, sinemalar, sanat merkezleri, amatör ve profesyonel spor kulüpleri ve diğer tüm rekreasyonel işletmeler, talep sahibine makul fiyatlı rekreasyonel faaliyetler düzenlemek için motive edilmelidir. Örgün ve yaygın eğitimde, kişiler ve ebeveynler rekreasyon bilinci, YD'nu artırmanın yolu, sağlık, esenlik ve mutluluk hakkında eğitilmelidir.

\section{References}

Ardahan, F. (2012). Life satisfaction and emotional intelligence of participants/ nonparticipants in outdoor sports: Turkey case, Procedia - Social and Behavioral Sciences 62:4-11.

Ardahan, F. (2016a). Volunteering as a Serious Leisure Activity: The case of AKUT. Mediterranean Journal of Humanities. 6(1): 47-61. DOI: 10.13114/MJH.2016119288.

Ardahan, F. (2016b). The Comparison of Life Satisfaction Level of Recreational Choir Singers and Non-Choir Singers. 4th International Academic Conference on Social Sciences. Proceedings book. July 28-29, 2016, Barcelona, Spain.

Ardahan, F., Karakucuk, S., Çetinkaya G., Akgül, B.M. and Kaplan Kalkan, A. (2017). Outdoor Recreation. Ed: Faik Ardahan. Detay Press. Ankara, Turkey.

Ardahan, F. (2018a). Developing and Doing Validity and Reliability of the Motivational Factor Scale of Being Choir Singer. European Journal of Physical Education and Sport Science.4(7):1-12. doi: 10.5281/zenodo.1249994 .

Ardahan, F. (2018b). For Getting More Life Satisfaction Being A Choir Singer In Golden Years. European Journal of Physical Education and Sport Science.4(5):1-17. doi: 10.5281 /zenodo.1239817.

Ardahan, F. (2018c). Comparison of the Social Capital, Life Satisfaction, Achievement Perception and Emotional Intelligence Level of the Volunteers and Non-Volunteers. European Journal of Physical Education and Sport Science.4(6):45-68. doi: 10.5281/zenodo.1249064. 
Ardahan, F. (2021). Aktif katılım bireylerin yaşam doyumunu nasıl etkiler? Journal of Human Sciences, 18(4), 592-615. doi:10.14687/jhs.v18i4.6175

Ardahan, F. and Güleç, S. (2017). Developing and Doing Validity and Reliability of the Motivational Factors Scale of Recreational Motorcycle Usage. 5th International Academic Conference on Social Sciences. Proceedings Book. 27-28 th July 2017, Barcelona, Spain.

Ardahan, F. and Lapa Yerlisu, T. (2011). Outdoor recreation: the reasons and carried benefits for attending outdoor sports of the participants of cycling and/or trekking activities. International Journal of Human Sciences. 8(1): 1327-1341.

Ardahan, F. and Mert M. (2014). Profile of the Bike Users and Evaluation of Motivational Factors for Cycling with Respect to Some Demographic Variables: Example from Turkey. Türkiye Klinikleri Journal of Sports Sciences 6(2): 53-57.

Ardahan, F. and Turgut, T. (2013). Comparing the Motivational Factors of Recreational Fishers and Hunters, Life Satisfaction Level of Participants and Non Participants in These Activities: Turkey Case. The Online Journal of Recreation and Sport, 2(1): 1-11. (EBSCO)

Ardahan, F., Turgut, T. and Kaplan Kalkan, A. (2016). Her Yönüyle Rekreasyon ( ing: All About Recreation) Editor: Faik Ardahan. Detay Yayıncllk (Detay Press). Ankara/Turkey.

Bjørnskov, C., Dreher, A., and Fischer, J. A. (2008). Cross-country determinants of life satisfaction: Exploring different determinants across groups in society. Social Choice and Welfare, 30(1), 119173.

Crandall R. (1980). Motivation for leisure. Journal of Leisure Research, 12(1): 45-54.

Deci E.L. ve Ryan R.M. (1985). The general causality orientations scale: Self determination in personality. Journal of Research in Personality. 19:109-134.

Diener E. (1984). Subjective well-being. Psychological Bulletin 93, 542-575.

Diener, E., Emmons, R.A., Larsen, R.J., and Griffin, S. (1985). The Satisfaction with Life Scale. Journal of Personality Assessment. 49, 71-75.

Diener, E.D. (2000). Subjective Well-Being: The Science of Happiness and a Proposal for a National Index. American Psychologist. 55(1):34-43. DOI: 10.1037//0003-066X.55.1.34.

Diener, E.D. and Diener, M. (1995). Cross-Cultural Correlates of Life Satisfaction and Self-Esteem. Journal of Personality and Social Psychology. 68(4): 653-663.

Diener, E., Gohm, C. L., Suh, E. and Oishi, S. (2000). Similarity of the relations between marital status and subjective well-being across cultures. Journal of cross-cultural psychology. 31(4):419-436.

Engeström Y., Miettinen R. ve Punamaki R.L. (2003). Perspective On Activity Theory, Cambiridge University Press, Second Edition, NY, 10011-4211, USA, p.22-80.

Lii, F. (1999). The exercise motivation scale: Its multifaceted structure and construct validity. Journal of Applied Sport Psychology. 11:1, 97-115.

Helliwell, J.F. (2003) How's life? Combining individual and national variables to explain subjective well-being. Econ Modell 20:331-336.

Ibrahim H. and Cordes, K.A., (2002). Outdoor Recreation, Enrichment For a Lifetime (2 ${ }^{\text {nd }}$ Edition). Sagamore Publishing, Campaign IL.

Layand, R. (2003). Happiness: Has Social Science A Clue?. Lionel Robbins Memorial Lectures 2002/3. Delivered on 3, 4, 5 March 2003 at the London School of Economics. Available at: http://eprints.lse.ac.uk/47425/

Lee, J., Scott, D. ve Floyd, M.F. (2001) Structural inequalities in outdoor recreation participation: A multiple hierarchy stratification perspective. Journal of Leisure Research, 33(4), 427-449.

Levy J. (1979). Motivation for leisure: An intereactionist approach. In H. Ibrahim and R. Crandall (Eds.), Leisure: A psychological approach. Los Alamitos, CA: Hwong Publishing, p.12-42.

Manfredo, M. J. Driver, B.L. ve Tarrant, M.A. (1996). Measuring Leisure Motivation: A MetaAnalysis of the Recreation Experience Preference Scales. Journal of Leisure Research, 28 (3): 188-213.

Miller, J.W. (2005).Wellness: The history and development of a concept. Spektrum Freizeit. 1(1):84102.

Mull, R.F., Bayless, K.G., and Jamieson, L.M. (2005). Recreational Sport Management. Human Kinetics, Champaign. 
Ardahan, F. (2021). Aktif katılım bireylerin yaşam doyumunu nasıl etkiler? Journal of Human Sciences, 18(4), 592-615. doi: $10.14687 /$ jhs.v18i4.6175

Pavot, W. and Diener, E. (1993). Review of the satisfaction with life scale. Psychological Assessment. 5(2): 164-172.

Peterson, C., Park, N. and Seligman, M. E. (2005). Orientations to happiness and life satisfaction: The full life versus the empty life. Journal of happiness studies. 6(1):25-41.

Pintrich P.R. (2000). An Achievement Goal Theory Perspective on Issues in Motivation Terminology, Theory and Research, Contemporary Educational Psychology, 25: 92-104.

Roberts, G. (1993). Motivation in sport: Understanding and enhancing the motivation and achievement of children. In R. N. Singer, M. Murphy, ve C. K. Tennant (Eds.), Handbook of research on sport psychology (pp. 405-420). New York: Macmillan.

Rossman, R.J., Schlatter, E.B., (2000). Recreation Programming Design Leisure Experiences, (3rd Edition). Sagamore Publishing, Campaign IL.

Scott, D. and Munson, W. (1994). Perceived constraints to park usage among individuals with low incomes. Journal of Park and Recreation Administration, 12(4), 79-96.

Shin, D.C. \& Johnson, D.M. (1978). Avowed happiness as an overall assessment of the quality of life. Social indicators research. 5(1-4):475-492.

Solop, F.I., Hagen, K.K. ve Ostergen, D. (2001). Back to nature: Visiting or not visiting our national parks. Public Perspective, 12 (4), 41-43.

Stebbins, R. A. (1982). Serious leisure: A conceptual statement. Pacific Sociological Review, 25, 251-272.

Stebbins, R. A. (1992) Amateurs, Professionals, and Serious Leisure. Montreal, PQ and Kingston, ON: McGill-Queen's University Press.

Stebbins, R. A. (1997). Casual leisure: A conceptual statement. Leisure Studies, 16(1), 17-25.

Stebbins, R. A. (2007). Serious leisure: A perspective for our time. New Brunswick, NJ: Transaction. Wymer W., Riecken G. and Yavas U. (1996). Determinants of Volunteerism: A Cross-Disciplinary Review and Research Agenda. Journal of Non-profit \& Public Sector Marketing, 4(4): 3-26.

Stebbins, R. A. (1992). Amateurs, professionals and serious leisure. Montreal, QC: McGill-Queen's University Press.

Steg, L. (2005). Car use: lust and must. Instrumental, symbolic and affective motives for car use. Transportation Research Part A 39: 147-162.

White, T.H. (1975). Relative importance of education and income as predictors in outdoor recreation participation. Journal of Leisure Research, 7(3), 191-199.

White, S.C. (2008). But what is well-being? A framework for analysis in social and development policy and practice. In Conference on regeneration and wellbeing: research into practice, University of Bradford (Vol. 2425).

Wymer W., Riecken G. and Yavas U. (1996). Determinants of Volunteerism: A Cross-Disciplinary Review and Research Agenda. Journal of Non-profit \& Public Sector Marketing, 4(4): 326.

\section{Extended English Summary}

\section{Definition of Well-Being, Life Satisfaction, Wellness, Happiness}

Every human wants to have more happiness, higher life satisfaction (LS), physical and mental health (wellness), and well-being in their lifetime. These are the main determiner of the life. Philosophers, physicists, psychologists, medical specialist and all other scientists and prophets, clergymen, personal development specialist, business owner, politician, local managers and all others have long been concerned with the good, happy, satisfactory, high quality life and how it can be achieved, what the best and shortest way is. All these have same, common, different advice, way to reach/obtain to the main four determiners. These four determiners usually mix, but they have different meaning. All of those have an effect on and affected by others. 
To unclutter, it is better to define them briefly.

Wellness is defining as a holistic concept of physical, mental, spiritual health and social wellbeing to the 1950s, but later it was accepted as in six dimension as physical, occupational, social, spiritual, intellectual and emotional. Wellness; a) is continuum situation rather than a fixed state, b) is holistic approach to health comprehensive physical, social, mental, spiritual and cultural dimensions, c) describe the potential and helping individuals for having highest WB suitable for his/her capable, d) self-knowledge and self-integration are the majors for high level wellness, e) the individuals' mental wellness is his/her responsibility, and cannot be delegated (Miller, 2005).

Well-Being (WB) is general described with positive terms for condition of individual or group. It has three dimensions, the first is subjective dimension which concerns experience, perceptions and values (sense of meaning/meaninglessness, hopes, fears and aspirations, self-concept and personality, trust and confidence), second is material dimension which concerns standards of living and practical welfare (income, access to services and amenities, wealth and asset, physical health and (dis)ability, employment and livelihood activities, environmental quality) and the third is the relational which concerns personal and social relations (networks of support and obligation, social, political and cultural identities and inequalities, relations of love and care, violence, conflict and (in)security). WB cannot be objective or equal for everyone but it is subjective form of correlation/combination of these three dimensions. "Doing Well - Feeling Good, Doing Good - Feeling Well" is common formulation of WB. Doing well state the material dimension, Feeling good describe the subjective dimension of WB. Second part of this formula is usually used for developing countries. "Doing good" determine the many restrictive as condition, substructure, wage, opportunities, material, etc. and "Feeling well" indicates moral sense, health (White, 2008).

Happiness is not easy to define. It can be accepted as a basic motivation of human beings. Layand (2003) define it as "feeling good - enjoying life and feeling it is wonderful" and Diener (1984) define it as a subjective phenomenon "for which the final judge is whoever lives inside a person's skin". Happiness is sometimes an instant mood and sometimes longs for a lifetime. Sometimes is reaching target, sometimes is having journey on this target.

In the late past, it was accepted that wellbeing and happiness were in relation to hedonism. Hedonism doctrine was the one of the most important way to reach wellbeing and happiness but Aristuppus (435-366 BCE) and Epicurus (342-270 BCE) argue about ethical hedonism focused on minimizing pain and maximizing pleasure. The follower of this philosophy says "don't worry, be happy". But Aristotle's (384-322 BCE) were the first person standing in contrast to hedonism. His notion of eudemonia was being true to one's inner self or true happiness is related and a need one's virtues. The follower of Aristotle's philosophy says "Be all that you can be and Make a difference" (Peterson et al 2005).

LS has different definitions. Shin and Johnson (1978) defined it as "a global assessment of a person's quality of life according to his chosen criteria", Diener (1984) define it as subjective WB, in another study Diener (2000) define it as "people's affective and cognitive evaluations of their lives" and Diener et al (1985) define it as important components of "good life", Pavot and Diener (2018) made another definition as decision and/or sensation of persons's life, emotional attitude toward his life and realization level of expectations"

As it seen in their definition they have really similar meaning but they are different and colloquial use of each.

\section{Importance of Life Satisfaction}

Satisfaction term has many meaning when it come together with different concepts like LS, Leisure Satisfaction, Role and Marital Satisfaction, Job Satisfaction, Occupational Satisfaction, Emotional Satisfaction, Social Satisfaction, Professional and Economic Satisfaction, and etc. Satisfaction can be defined as realization level of expectations (Ardahan, 2018b). All these satisfaction affect others and affected from them. There is a positive correlation between them. At the same time, all these satisfactions affect and are affected from individual's physical, mental, emotional 
life/healthy, professional and social interaction, WB, wellness, and happiness. Other parameters which have an effect on individuals LS can be listed as following; a) having meaningful relation/interaction with wife/husband, partner, children, family members, social friends, collages, relatives and others, b) having sufficient personal and family income to support all expectations, satisfactory job and occupational satisfaction or professional life, having satisfactorily financial satisfaction, c) physical, mental emotional, social, spiritual, and intellectual wellness, d) having satisfactorily neighbourhood and living in well-equipped environment, e) having pleasure retrieved from social and professional life, e) material things like house, hobby equipment, car/motorbike, clothes and etc. f) having hobbies and leisure life, g) having high quality of life, i) having positive personality, j) having satisfactorily sexual life, $\mathrm{k}$ ) those who want children and have children physically and mentally well, and other things (Diener et al. 1985; Diener, 1984; Pavot and Diener, 1993; Ardahan, 2018b). While having something increases LS, sometimes having same thing may decrease LS. For example, even if literature say materials things affect LS positive, for low income person having car can bring trouble for bearing the cost. While being in love married/partnership increase LS, sometimes being alone affect LS positive. How things affect LS is depend on present conditions. It can be change person to person, time to time, culture to culture.

Satisfied soul is happy and/or ready to be happy or being happy effect positive soul. It can be said for having positive wellness too. Happy soul and positive wellness usually can be accepted as an open door for having higher LS. In many research results it is demonstrated that there are positive correlation between LS and happiness, LS and wellness (Diener, 2000; Ibrahim and Cordes, 2002; Ardahan, 2018b).

\section{Importance of Recreational Life}

Daily life can be divided into three parts. These are work or school time, sleep time and other time. Work, school and sleep time can be defined as obligations. Other time include recreational life or leisure life and some social obligations as personal care, childcare, housework (cleaning, cooking), shopping (Ardahan et al. 2016). While some researchers categorize social obligations under recreational life, some doesn't.

Recreational life or leisure life can be defined as the sum of the enjoyable activities that individuals can do alone or within a group in their free time with their free will, and as a result, they enjoy, get physically and mentally refreshment, regeneration and enjoyment (Rossman and Schlatter, 2000; Ibrahim and Cordes, 2002). Recreational life requires active or passive participation to get happiness, wellness, wellbeing and LS as given in Figure-1. While passive participation is being audience, active participation is doer (Mull et al. 2005). If football taken as an example, players, referees and technical staffs can be accepted as active participants, audiences in football ground and on TV are passive participants. Some leisure activities require interactive participation like workshops. Interactive participation can be accepted as active participation (Ardahan et al. 2016).

In daily life, while passive participation is being audience; active participation can be recreational, amateur or professional. Some part of the amateur participation can be accepted recreational and the rest is professional. The audience potential increases trough to professional life in all kind of activity. In recreational life, audiences are usually family members, close friends and neighbors, in amateur life; audience consisted of usually far and near family members, all friends and some followers, but in professional life, audiences are usually followers who create a social belonging. 
Ardahan, F. (2021). Aktif katılım bireylerin yaşam doyumunu nasıl etkiler? Journal of Human Sciences, 18(4), 592-615. doi:10.14687/jhs.v18i4.6175

Figure-1: Participant Type and Audience Potential

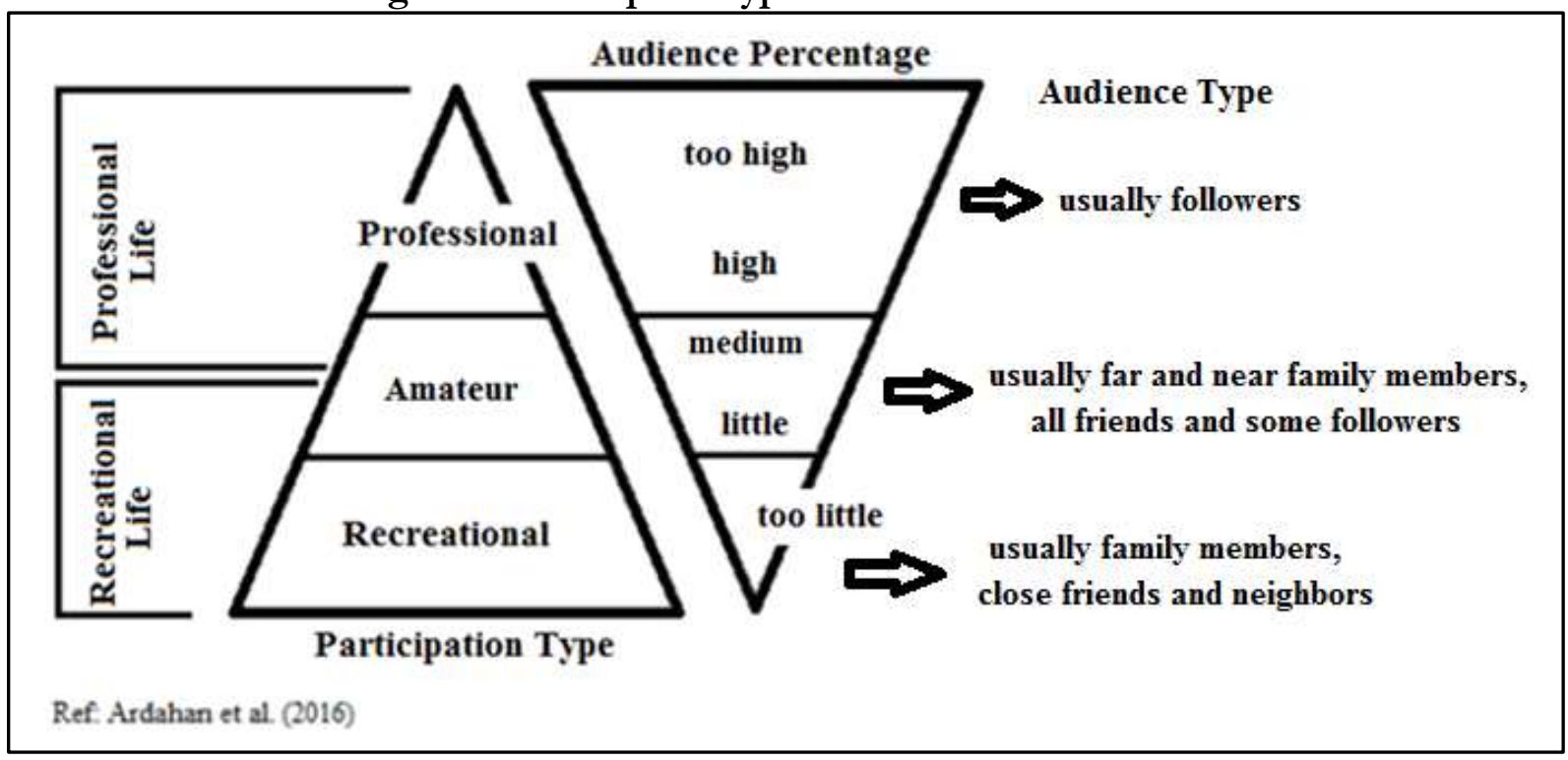

All leisure researchers conclude that both passive and active participation into recreational activities have positive effect on LS. For that reason leisure participation is an important for wellness, wellbeing and happiness. The benefits of leisure participation can be accepted as a door to higher LS. When compared, active participation has potentially higher positive effect on LS than passive participation. Both active and passive participation has superior positive effect on LS than nonparticipation (Diener, 2000; Ardahan, 2012, 2016a, 2016b). In this paper, the effect of active participation and non-participation on LS was compared.

There is a correlation between reasons and the benefits. Usually expected benefits define our behaviour. The benefits of leisure participation are a) develop physical and mental health, b) socialize individuals, c) increase self-confidence, d) develop presents and gain new ability and skills, e) give individual social career opportunity, f) develop creative power and aesthetic perception, g) give satisfaction, happiness, wellness and wellbeing, $h$ ) increase productivity and achievement perception, i) provide social solidarity and integration, $j$ ) allow the creation of a democratic society, $k$ ) increase life quality of individuals and society, l) increase social capital, $\mathrm{m}$ ) create belonging to somewhere or a group, n) give self-expression and self-realization opportunity, o) increase mobility, p) create economy and positive effects on many sectors, s) give opportunity to have richer family, friendship and neighbourhood life and interaction, $\mathrm{t}$ ) develop intellectual life and vision, $\mathrm{u}$ ) improve social relations, provide solidarity and mutualisation, v) enriching the cultural life of society, y) decrease all kind dependency, z) prevent sickness, shorten the duration of treatment and create physical and mental terapic effect (Manfredo et al. 1996; Ibrahim and Cordes, 2002; Ardahan et al. 2016).

The big question is that "all recreational participation has same effect on LS?" the answer is "no". The effect can be change time to time, person to person. Stebbins answer for this question may be the best.

Stebbins (1992) categorised recreational life in three categories as casual leisure, project based leisure and serious leisure. Casual leisure is usually hedonic, short term, gleesome, randomly and unorganised chosen activities which require no special training for doing or participate it like play, relaxation, passive entertainment, sociable conversation, sensory stimulation (Stebbins, 1997). Project based leisure activities require well or half equipped skills and knowledge for regular but infrequent, one-shot or occasional participation (like dancing only in wedding ceremony, singing only religious rite, participation spring festival, art festival, sports events). Serious leisure activities are the life style, need to persevere at activity, give leisure and social career without any professional expectation, and require well or high equipped skills and knowledge, hobbyist and volunteer participation, and 
Ardahan, F. (2021). Aktif katılım bireylerin yaşam doyumunu nasil etkiler? Journal of Human Sciences, 18(4), $592-615$. doi:10.14687/jhs.v18i4.6175

realization of some special benefits (Stebbins, 1982, 2007). Serious leisure has permanent positive affect on LS. Project based leisure activities has positive effect on LS when done but require regular repetition. Casual leisure activities are hedonic and have positive effect on LS.

Casual leisure activities can be accepted like Basic Needs in Maslow Need Theory, to get the benefits and positive effect on LS, repetition is necessary. Many individuals' recreational life is at that level. Project based leisure Psychological/Middle Needs in Maslow Need Theory just like belongingness and love needs. This is strong effect than casual leisure. But the most effective effect on LS is having serious recreational life. It satisfies self-fulfilment need.

The Relation between Motivation Theories and LS

The big and main question is that "what determine our behaviour? And how do our decisions and behaviour affect our LS?" Many researchers answer this question from their windows. But, this question have not been answered clearly yet. Decisions define direction of our life, owned and abandoned things. Wymer et al. (1996) explain the answer by using "Values, Attitudes and Behaviour relation model". Crandall (1980) concluded that behaviour is the result of interaction between identity and conditions, Levy (1979) concluded that behaviour is the result of interaction between identity and social, economic, neighbourhood and environmental condition. For example, if everybody rejects using something in a society, someone usually cannot demand it because of the community pressure or vice versa. Some researcher used motivation theories to answer this question. Deci and Ryan (1985) explain the reason of our behaviour by using The Self-Determination Theory. There are three dimensions of motivation in this theory as extrinsic motivation, intrinsic motivation and amotivation. Participation or nonparticipation into recreational activities can be the result of this motivation types (Lii, 1999). In addition to these, Pintrich (2000) conclude the reason of our behaviour by using The Achievement Goal Theory. This theory has two types of goals. Ego (performance) Goals which give desire to become a leader, compete with other, challenge with something/somebody, desire of recognition, be approved and task oriented goals which give social sensitivity, helping others, compete with himself, challenge himself, get new skills, having socially wellbeing and social solidarity (Roberts, 1993). Ego goals and Task oriented goal usually define individual's identity and values and affect LS of individuals. Engeström et al. (2003) explain the reason of behaviour by using The Activity Theory. Activity theory has four types behaviour as object, internalization/externalization, mediation and development oriented activities. Activity theory usually focuses on successful aging, physically, mentally and emotionally sufficiency. And these sufficiencies have positive effect on LS. Another motivation theory is the Steg's (2005) Motivation for Vehicle Use Theory which concludes instrumental, symbolic and affective motives of having/using a car or something. The last and well-known motivation theory is Need Theory developed by Maslow used to answer the main question (Ibrahim and Cordes, 2002). In this theory, it concludes that needs motivate individuals to satisfied them and when satisfied, it gives satisfaction. As known it has five step hierarch of needs and dimensions as Physical Dimension, Physiological Needs (clothing, food, shelter, sex, etc.), Environmental dimension, Safety Needs (personal, emotional and financial security, healthy and well-being, needs against accidents/illness), Sociocultural Dimension, Belonging and Love Needs (friendship, intimacy, family, to a group, organisation, nation, sub culture), Emotional Dimension, Self-Esteem Needs, Intellectual and Spiritual Dimensions, SelfActualization, and Self-Transcendence Needs.

Recreation is a need from first stage to upper. Physiological Needs as food and drinking Safety Needs as all kind security is basic need, at the same time satisfaction all these needs as having a dinner, exercising for wellness can be a leisure activity. Belonging to a group, family or organisation is a need and participating leisure activity gives/creates this change and satisfaction. Self-Esteem Needs, Self-Actualization and Self-Transcendence Needs is upper level needs and when participate a recreational activity to satisfied these needs it is usual serious leisure activity and give/create higher level satisfaction. 
Ardahan, F. (2021). Aktif katılım bireylerin yaşam doyumunu nasıl etkiler? Journal of Human Sciences, 18(4), 592-615. doi:10.14687/jhs.v18i4.6175

\section{Demographics Variables and LS}

Many researchers studied how demographics variables affect LS. It is clear that income has positive effect on LS and there is positive correlation between them. When compared, it can be said that employed individuals have higher LS than retired and unemployed ones depending on financial welfare and other satisfaction related with working (Diener, 1984, 2000; Diener et al. 1985; Helliwell, 2003; Bjørnskov et al. 2008; Ardahan, 2012, 2016b, 2018b, 2018c).

Even if many married individuals want to participate alone into his/her preferred leisure activity meaningful marriages support couples recreational life positively. In addition to this, marriage give couples having children opportunity, social support, create collectivism (the smallest team activity) and these also increase or have positive effect on LS (Diener et al. 2000; Helliwell, 2003; Bjørnskov et al. 2008; Ardahan, 2012, 2016b, 2018b, 2018c). Education can be accepted as climbing up like in mountaineering. If the weather (your mind) is open and if you are on enough high altitude (have well educated) you can see far away. It increases awareness level, capability of long-sightedness and problem solving. It has positive effect on LS (Diener, 1984, 2000; Diener et al. 1985; Helliwell, 2003; Bjørnskov et al. 2008; Ardahan, 2012, 2016b, 2018b, 2018c). Even if Diener and Diener (1995) concluded that men and women have very close LS, recent studies show that women has higher LS in many country including Turkey (Ardahan, 2012, 2016b, 2018b, 2018c).

Age is the other important determiner of leisure demand type and LS. While young prefer usually the leisure activities need higher physical performance, take higher risk, this goes down by aging. The young do not hesitate about future; they have income without working, and more physical energy, higher self-confidence and LS. Then, when they finish their education life they fight for professional and social carrier (marriage, children, buying home, car etc.) until middle age. After this age, they usually realize many of target, solve professional and social career and usually neglect themselves, then, they return their own life and enrich their recreational life, with high self-realization. Usually when age increase, individuals' professional carrier advance, therefore, individuals have higher income, economic welfare and this give rise to higher LS (Ardahan, 2018b).

\section{Method}

The main aim of this research was to compare Life Satisfaction (LS) level of individuals who have active participation into some recreational activities with individuals who do not have active participation into same recreational activities with respect to some demographics as age, gender, marital status, personal income, employment type, education level and recreational activities.

The sample of the study is composed of 4214 men and 1287 women, totally 5501 individuals. Data composed from thirteen different researches focused on recreational activities and LS. Nine of them have active participants in bicycle festivals (Ardahan and Lapa Yerlisu, 2011), mountaineering/rock climbing (Ardahan, 2012), trekking/hiking (Ardahan, 2012), hunting (Ardahan and Turgut, 2013), fishing (Ardahan and Turgut, 2013), recreational bicycle users (Ardahan and Mert, 2014), recreational motorcycle users (Ardahan and Güleç, 2017), being volunteer in a nongovernmental organisation (Ardahan, 2016b), singing in recreational choirs as a chorist (Ardahan, 2016b), and four of them consist of individuals never done this kind of activity before, as never participate in any outdoor activities (Ardahan, 2012), never hunting and fishing (Ardahan and Turgut, 2013), never been in a choir as a chorist (Ardahan, 2016b), never been as a volunteer in any nongovernmental organisations (Ardahan, 2018c).

From each data set demographic variables; gender, marital status, education level, age, employment type were taken how as is, but some arrangements done on personal monthly income with respect to official minimum wage and US\$ base year 2018 was approved as 100 .

In the analysis of data, besides the descriptive statistics, Independent Sample t-test and ANOVA test were used, thus to identify the reason of the differences, LSD test were applied. All the results were analyzed at the significant levels of 0.05 . 


\section{Findings}

Demographics variables of this research were given in Table-1. As it seen in Table-1, majority of the participants were men, single, well educated, 44 years old and younger, have about $700 €$ monthly personal income, employed in public or private sector or self-employed, consisted of individuals who has active participants in one of outdoor leisure activity or volunteer in a NGO or choir singers.

Table-1: Demographics Variables

\begin{tabular}{lcclcc}
\hline Demographic Variables & $\mathbf{n}$ & $\mathbf{0}$ & $\begin{array}{l}\text { Demographic } \\
\text { Variables }\end{array}$ & $\mathbf{n}$ & $\mathbf{\%}$ \\
\hline Participate in Mountaineering/Rock & 426 & 7,70 & Private Sector Employee & 1783 & 32,40 \\
Climbing & & & & & \\
Participate in Bicycle Festival & 373 & 6,80 & Public Sector Employee & 925 & 16,80 \\
Participate in Trekking/Hiking & 382 & 6,90 & Self Employed & 1221 & 22,20 \\
Never participate in any outdoor activities & 538 & 9,80 & House Wife & 140 & 2,50 \\
Participate in Hunting & 187 & 3,40 & Students & 847 & 15,40 \\
Participate in Fishing & 367 & 6,70 & Retired & 381 & 6,90 \\
Never Hunting and Fishing & 324 & 5,90 & Unemployed & 204 & 3,70 \\
Recreational Motorcycling & 947 & 17,20 & $350 €$ and below & 1287 & 23,40 \\
Being Volunteers in a NGO & 208 & 3,80 & $351-700 €$ & 1529 & 27,80 \\
Never been as a Volunteer & 138 & 2,50 & $701-1050 €$ & 1189 & 21,60 \\
Being chorist in recreational choirs & 633 & 11,50 & 1051 $€$ and more & 1496 & 27,20 \\
Never been in a choir as a chorist & 296 & 5,40 & 24 years old and below & 1116 & 20,30 \\
Recreational bicycling & 682 & 12,40 & $25-34$ years old & 1649 & 30,00 \\
\hline Men & 4214 & 76,60 & $35-44$ years old & 1209 & 22,00 \\
Women & 1287 & 23,40 & $45-54$ years old & 877 & 15,90 \\
\hline Married & 2262 & 41,10 & 55 years old and more & 650 & 11,80 \\
Single & 3239 & 58,90 & High School and below & 1526 & 27,70 \\
\hline Individuals who are active participations & 4205 & 76,40 & University and upper & 3975 & 72,30 \\
Individuals who are non-participations & 1296 & 23,60 & Total & $\mathbf{5 5 0 1}$ & $\mathbf{1 0 0 , 0 0}$ \\
\hline
\end{tabular}

$\overline{\mathbf{P S}}=1 €=3.58 \mathrm{TL}$ in 1 th May 2017

LS level of participants and comparison of LS level with respect to demographics variables were given in Table-2. As seen in Tablee-2, having active leisure life and participating in recreational activities increase individuals' LS level. When LS level of individuals participating in Trekking/Hiking, Motorcycling, Mountaineering/Rock Climbing, Bicycling, Hunting, Fishing, Bicycle Festival, volunteering, and recreational choirs as chorist compare with the individuals who do not participate in these leisure activities, there is statistically meaningful positive difference in favour of active participation. The highest LS is in volunteers in a NGO. In addition to this, women has higher LS than men, married has higher LS than singles, self-employed, retired individuals, and public sector employee have higher LS than others, individuals higher personnel monthly income have higher LS, individuals higher ages have higher LS. In contrast this, education level differences is not a reason to have higher/lower LS. 
Ardahan, F. (2021). Aktif katılım bireylerin yaşam doyumunu nasıl etkiler? Journal of Human Sciences, 18(4), 592-615. doi:10.14687/jhs.v18i4.6175

Table-2: Life Satisfaction of Participants/Non-Participants and Comparison of LS Level With Respect to Demographics Variables

\begin{tabular}{|c|c|c|c|}
\hline Demographic Variables & Mean \pm SD & Demographic Variables & Mean \pm SD \\
\hline Participate in Trekking/Hiking & $3,38 \pm 0,759$ & Participate in Hunting & $3,38 \pm 0,673$ \\
\hline Recreational Motorcycling & $3,38 \pm 0,841$ & Participate in Fishing & $3,38 \pm 0,707$ \\
\hline $\begin{array}{l}\text { Participate in Mountaineering/Rock } \\
\text { Climbing }\end{array}$ & $3,28 \pm 0,836$ & Never Hunting/Fishing & $2,94 \pm 0,929$ \\
\hline Recreational bicycling & $3,24 \pm 0,728$ & Self Employed & $3,39 \pm 0,808$ \\
\hline Participate in Bicycle Festival & $3,16 \pm 0,823$ & Retired & $3,34 \pm 0,770$ \\
\hline Never participate in any outdoor activities & $3,08 \pm 0,925$ & Public Sector Employee & $3,33 \pm 0,774$ \\
\hline Being Volunteers in a NGO & $3,53 \pm 0,506$ & Students & $3,24 \pm 0,824$ \\
\hline Never been as a Volunteer & $3,27 \pm 0,997$ & Private Sector Employee & $3,23 \pm 0,829$ \\
\hline Being chorist in recreational choirs & $3,45 \pm 0,822$ & House Wife & $3,20 \pm 0,961$ \\
\hline Never been in a choir as a chorist & $3,11 \pm 0,868$ & Unemployed & $2,94 \pm 1,031$ \\
\hline$\overline{\text { Men }}$ & $3,25 \pm 0,827$ & $350 €$ and below & $3,08 \pm 0,875$ \\
\hline Women & $3,36 \pm 0,824$ & $351-700 €$ & $3,29 \pm 0,814$ \\
\hline$\overline{\text { Married }}$ & $3,34 \pm 0,793$ & $701-1050 €$ & $3,31 \pm 0,847$ \\
\hline Single & $3,24 \pm 0,848$ & $1051 €$ and more & $3,41 \pm 0,748$ \\
\hline Individuals who are active part & $3,34 \pm 0,784$ & 24 years old and below & $3,21 \pm 0,883$ \\
\hline Individuals who are non-participations & $3,07 \pm 0,925$ & $25-34$ years old & $3,21 \pm 0,821$ \\
\hline High School and below & $3,27 \pm 0,849$ & $35-44$ years old & $3,29 \pm 0,829$ \\
\hline University and upper & $3,28 \pm 0,819$ & $45-54$ years old & $3,35 \pm 0,776$ \\
\hline Statistical Comparison & $\mathbf{t}$ & 55 years old and more & $3,45 \pm 0,776$ \\
\hline$\overline{\text { Gender }}$ & $-4,176^{*}$ & Statistical Comparison & $\mathbf{F}$ \\
\hline Marital Status & $4,304 *$ & Recreational Activity & $15,426^{*}$ \\
\hline Education Level & $-0,257$ & Age & $13,361 *$ \\
\hline Active Participation & $9,558 *$ & Personal Income & $39,738^{*}$ \\
\hline * $\mathrm{p}<0.05$ & & Employment Type & $11,776^{*}$ \\
\hline
\end{tabular}

Comparison of active participants' and non-participants' LS level with respect to Education Level, Gender, Marital Status, Age, Personal Income, Employment Type and some recreational activity were given in Table-3. As it seen in Table-3; in all comparison of active participants' LS and non-participants' LS, there is statistically meaningful difference in favour of active participants.

While there is no statistically meaningful difference on LS between two different education levels in active participation, there is statistically meaningful difference on LS in favour of university and upper education level in non-participation.

LS level change with respect to gender. In active and in non-participation, there is positive statistically meaningful difference on LS in favour of women.

A marriage is the smallest team and emotional cooperation. While there is positive statistically meaningful difference on LS in favour of marrieds in active participation, there is no statistically meaningful difference on LS between married and singles in non-participation.

In active and in non-participation, there is positive statistically meaningful difference on LS in favour of upper aged individuals and higher personal income.

While there is negative statistically meaningful difference on LS in con of unemployment in active participation, there is negative statistically meaningful difference on LS in con of unemployment and housewife in non-participation. 
Ardahan, F. (2021). Aktif katılım bireylerin yaşam doyumunu nasıl etkiler? Journal of Human Sciences, 18(4), 592-615. doi:10.14687/jhs.v18i4.6175

Table-3: Comparison of Participants and Non-Participants' LS Level With Respect to Education Level, Gender, Marital Status, Age, Personal Income, Employment Type and Some Recreational Activity

\begin{tabular}{|c|c|c|c|c|c|}
\hline \multirow[t]{2}{*}{$\begin{array}{l}\text { Demographic } \\
\text { Variable }\end{array}$} & \multicolumn{2}{|c|}{ Active Participation } & \multicolumn{2}{|c|}{$\begin{array}{c}\text { Non- } \\
\text { Participation }\end{array}$} & \multirow[t]{2}{*}{$\begin{array}{c}\text { Statistic } \\
\text { t/F }\end{array}$} \\
\hline & $\mathrm{n}$ & Mean \pm SD & $\mathrm{n}$ & Mean \pm SD & \\
\hline High School and below & 1349 & $3,33 \pm 0,828$ & 177 & $2,90 \pm 0,907$ & $6,384 *$ \\
\hline University and upper & 2856 & $3,35 \pm 0,762$ & 1119 & $3,10 \pm 0,926$ & $8,120 *$ \\
\hline Comparison by education level $(\mathrm{t})$ & & $-1,048$ & & $-2,716^{*}$ & \\
\hline Men & 3382 & $3,32 \pm 0,785$ & 832 & $2,97 \pm 0,934$ & $9,464 *$ \\
\hline Women & 823 & $3,44 \pm 0,773$ & 464 & $3,22 \pm 0,891$ & $4,437 *$ \\
\hline Comparison by gender $(\mathrm{t})$ & & $-4,054 *$ & & $-4,439 *$ & \\
\hline Married & 1885 & $3,38 \pm 0,771$ & 377 & $3,13 \pm 0,867$ & $5,115^{*}$ \\
\hline Single & 2320 & $3,32 \pm 0,793$ & 919 & $3,05 \pm 0,948$ & $7,599 *$ \\
\hline Comparison by marital status $(\mathrm{t})$ & & $2,514 *$ & & 1,480 & \\
\hline 24 years old and below & 657 & $3,29 \pm 0,819$ & 459 & $3,10 \pm 0,956$ & $3,363 *$ \\
\hline 25-34 years old & 1266 & $3,29 \pm 0,763$ & 383 & $2,97 \pm 0,952$ & $5,879 *$ \\
\hline $35-44$ years old & 1027 & $3,33 \pm 0,798$ & 182 & $3,06 \pm 0,959$ & $3,535 *$ \\
\hline $45-54$ years old & 687 & $3,43 \pm 0,763$ & 190 & $3,07 \pm 0,758$ & $5,740 *$ \\
\hline 55 years old and more & 568 & $3,46 \pm 0,768$ & 82 & $3,39 \pm 0,829$ & 0,843 \\
\hline Comparison by age $(\mathrm{F})$ & & $7,937 *$ & & $3,631^{*}$ & \\
\hline $350 €$ and below & 802 & $3,16 \pm 0,811$ & 485 & $2,94 \pm 0,954$ & $4,349 *$ \\
\hline $351-700 €$ & 1191 & $3,35 \pm 0,791$ & 338 & $3,08 \pm 0,862$ & $5,404 *$ \\
\hline $701-1050 €$ & 943 & $3,37 \pm 0,792$ & 246 & $3,09 \pm 1,004$ & $4,131 *$ \\
\hline $1051 €$ and more & 1269 & $3,43 \pm 0,735$ & 227 & $3,33 \pm 0,808$ & $1,785 *$ \\
\hline Comparison by monthly income $(\mathrm{F})$ & & $19,685^{*}$ & & $9,289 *$ & \\
\hline Private Sector Employee & 1400 & $3,27 \pm 0,791$ & 383 & $3,06 \pm 0,936$ & $4,107 *$ \\
\hline Public Sector Employee & 706 & $3,39 \pm 0,718$ & 219 & $3,12 \pm 0,901$ & $4,135 *$ \\
\hline Self Employed & 1074 & $3,41 \pm 0,780$ & 147 & $3,18 \pm 0,969$ & $2,753 *$ \\
\hline House Wife & 82 & $3,49 \pm 0,758$ & 58 & $2,79 \pm 1,067$ & $4,297 *$ \\
\hline Students & 497 & $3,29 \pm 0,787$ & 350 & $3,19 \pm 0,871$ & $1,752 *$ \\
\hline Retired & 297 & $3,42 \pm 0,795$ & 84 & $3,07 \pm 0,602$ & $4,137 *$ \\
\hline Unemployed & 149 & $3,19 \pm 0,932$ & 55 & $2,24 \pm 0,968$ & $6,313 *$ \\
\hline Comparison by employment type $(\mathrm{F})$ & & $5,961 *$ & & $10,064 *$ & \\
\hline Participating in one of out & 2810 & $3,30 \pm 0,804$ & 538 & $3,08 \pm 0,925$ & $5,206^{*}$ \\
\hline Participating in Hunting or Fishing & 554 & $3,38 \pm 0,695$ & 324 & $2,94 \pm 0,929$ & $7,400 *$ \\
\hline Being Volunteers in a NGO & 208 & $3,53 \pm 0,506$ & 138 & $3,27 \pm 0,997$ & $2,808 *$ \\
\hline Being chorist in recreational choirs & 633 & $3,45 \pm 0,822$ & 296 & $3,11 \pm 0,868$ & $5,654 *$ \\
\hline
\end{tabular}

\section{Conclusion}

In this study, effect of life satisfaction of respondents who have active participation into some recreational activities were studied with respect to some demographics variables as age, gender, marital status, personal income, employment type, education level and recreational activities.

Results show that active participation into recreational activities has positive effect on LS. Many studies have done in Turkey, in other countries and recreation theories verify/support this result. Each active participated recreational activity studied in this paper as mountaineering, sport climbing, riding mountain bike, riding motorbike, hiking/trekking can be accepted as similar activities, but fishing, hunting, volunteering, participating into bicycle festival, being chorist in recreational choirs have different character, required different physical and mental abilities and when 
Ardahan, F. (2021). Aktif katılım bireylerin yaşam doyumunu nasıl etkiler? Journal of Human Sciences, 18(4), $592-615$. doi:10.14687/jhs.v18i4.6175

compared with non-participants, each of them creates positive effect on LS (Pavot and Diener, 1993; Manfredo et al. 1996; Diener, 1984, 2000; Ibrahim and Cordes, 2002; Ardahan, 2012, 2016a, 2016b). Motivation theories also support active participation's positive effect on LS (Deci and Ryan, 1985; Diener at al. 1985; Roberts, 1993; Diener and Diener; 1995; Lii, 1999; Pintrich, 2000; Ibrahim and Cordes, 2002; Engeström et al. 2003; Helliwell, 2003; Steg, 2005; Ardahan, 2012, 2016a, 2016b; Ardahan et al. 2016).

In many studies, it was found that the demand of recreational activities can vary by demographics variables (Ardahan, 2012), but LS may not change by demographic variables. In Ardahan's (2016a, 2016b, 2018b) studies LS of participants has active serious leisure life in both gender were found very similar. When LS was compared by gender, there are statistically meaningful differences between groups in active participants in favor of women and in non-participants in favor of women, between the active participant's men and non-participant's men in favor of active men, between the active participant's women and non-participant's women in favor of active women. Women are lucky for having higher LS or in other words they create their changes, they manage their conditions better than men (Ardahan, 2012, 2016b, 2018b, 2018c). In contrast, even if this Diener and Diener (1995) conclude men and women have very close LS, recent studies show that women have higher LS in many countries.

Income is one of the main positive determiners of LS (Diener at al. 1985) and in many study, it was found that when income increases, LS level of increases (White, 1975; Scott and Munson, 1994). Lee at al. (2001) and Solop et al. (2001) conclude that advance in education level, personal income and employment status have positive impact on recreation demand. The results of this study support this scientific truth. It is found in active participants group and non-participants, when income increase, LS increases too. In addition to this conclusion, if was found that employed individuals have higher LS than unemployed ones depending on financial welfare and other satisfaction related by working in active participants and in non-participants. But active participant's LS level in all employment type has higher than non-participants. The conclusion of Diener (1984, 2000), Diener et al. (1985), Helliwell (2003), Bjørnskov et al. (2008), and Ardahan (2012, 2016b, 2018b, 2018c) support this results.

Education is just like a stairs and it gives professional, recreational and social wisdom (Ardahan et al. 2016, Ardahan et al. 2017) and it increases awareness level, capability of longsightedness and problem solving and has positive effect on LS (White, 1975; Diener, 1984, 2000; Diener et al. 1985; Lee at al. 2001; Solop et al. 2001; Helliwell, 2003; Bjørnskov et al. 2008; Ardahan, 2012, 2016b, 2018b, 2018c). This conclusion supports the result of current study. When compared with active participants and non-participants, it was found that active participation give statistically meaningfully higher LS than non-participants in both education level. In addition to this, when compared education level, while there is no statistically meaningful differences in active participants group, there is statistically meaningful differences in differences in non-participants group. These results show that education has positive effect on LS level.

In recreation literature marriage/ couple life not accepted as a border for participation leisure activities (Ardahan et al. 2016, Ardahan et al. 2017, Ibrahim and Cordes, 2002). Satisfactorily marriage or couple life support for having active participation. These conclusion overlaps with the results of this study. While in active participants group married participants have higher LS than singles and statistically meaningful differences in favor of marrieds, in non-participants groups married participants have higher LS than singles and but there is no statistically meaningful differences between singles and marrieds. When compared active participants and non-participants, it was found that active participation give statistically meaningfully higher LS both marrieds and singles than nonparticipants. All these overlaps with the studies of Diener et al. (2000); Helliwell (2003), Bjørnskov et al. (2008), Ardahan, (2012, 2016b, 2018b, 2018c).

As concluded in recreation literature (Ardahan, 2018b), in the result of current study, age has higher LS in 25 years old and below and 55 years old and more in both group active participants and 
non-participants. When compared active participants' and non-participants' LS, there are statistically meaningful differences in favor of active participants. Results overlap with literature.

\section{Results}

Findings demonstrate that being women, married, employed, in middle aged and/or upper, in active leisure life and have higher personal income cause statistically meaningful higher LS then opposites. In addition to this, having active leisure life give rise to have positive affect on LS level of individuals. When compared with respect to each demographics variable there are statistically meaningful differences LS levels between individuals who are active participants of some recreational activities and non-participate into same activities.

As a result, it can be concluded that for having higher LS level, it is necessary to have active leisure life or active participation in any recreational activities. For this in each level of education stage, individuals must be educated and motivated how to be an active leisure life, what the active life's advantages are and the urban design and infrastructural investments must support and motivate recreational life of urbanites.

It is important and advised that active participation and passive participation should be studied in further studies for revealing their effect on LS. Public and private enterprises, municipalities, universities, non-governmental organizations, theatres, cinemas, art centers, amateur and professional sport clubs and all other recreational enterprises must be motivated to organize reasonable priced recreational activities to requisitioner. In formal and informal education, persons and parents should be educated about recreation conscious, the way of increasing LS, wellness, wellbeing and happiness. 